\title{
Fractionational and structural characterization of lignin and its modification as biosorbents for efficient removal of chromium from wastewater: a review
}

\author{
Bing Wang ${ }^{1+}$, Yong-Chang Sun ${ }^{2+}$ and Run-Cang Sun ${ }^{3^{*}}$
}

\begin{abstract}
The removal of chromium ( $\mathrm{Cr}$ ) from wastewater by various adsorbents has been investigated. As compared with the commercial activated carbon, the biosorbents with inexpensive and high adsorption capacities are developed from lignocellulosic wastes. Lignin, existing in lignocellulosic biomass, is the second most abundant resource in nature. Recently, lignin-based bio-sorbents were served as an advanced novel material for the metal ions and dye adsorption from wastewater. It has showed several advantages in the wastewater treatments because of the lowcost, high adsorption capacity, easy recover, and possibility of metal recovery. In this review, the isolation of lignin from lignocellulosic biomass was summarized, and the structural characteristics of lignin were comparably analyzed. The modification of lignin was performed to obtain a large surface area, strong binding-site, and high and quick adsorption properties of lignin-based adsorption materials. The adsorption efficiency of $\mathrm{Cr}$ ions was found to be strongly dependent on the $\mathrm{pH}$ of the wastewater. To further illustrate the adsorption process, the structural changes and the interactions between the metal ions and the functional groups of the lignin-based biosorbents in the adsorption process should be further investigated. Once the cost-effective and high-efficiency modification techniques are developed, lignin-based adsorbents can be expected to be the most suitable alternatives for $\mathrm{Cr}$ ions removal from wastewater in industry.
\end{abstract}

Keywords: Lignocellulosic biomass, Lignin, Adsorption, Wastewater, Chromium

\section{Introduction}

With the flourish of several industry, such as dyes and pigment manufacturing, leather tanning, electroplating, and mining, etc., the use of chromium $(\mathrm{Cr})$ chemicals leads to seriously water pollution $[1,2]$. The existing forms of chromium in effluents are $\mathrm{Cr}$ (III) ions $\left(\mathrm{Cr}^{3+}\right.$, $\mathrm{Cr}(\mathrm{OH})^{2+}, \mathrm{Cr}(\mathrm{OH})_{3}{ }^{0}$ and $\left.\mathrm{Cr}(\mathrm{OH})_{4}^{-}\right)$and $\mathrm{Cr}(\mathrm{VI})$ ions $\left(\mathrm{Cr}_{2} \mathrm{O}_{7}{ }^{2-}, \mathrm{CrO}_{4}{ }^{2-}\right.$, and $\left.\mathrm{HCrO}_{4}^{-}\right)$, which are dependent on the $\mathrm{pH}$ and the $\mathrm{Cr}$ concentrations in the existing

\footnotetext{
* Correspondence: rcsun3@bjfu.edu.cn

${ }^{\dagger}$ Bing Wang and Yong-Chang Sun contributed equally to this work.

${ }^{3}$ Center for Lignocellulose Science and Engineering, and Liaoning Key

Laboratory Pulp and Paper Engineering, Dalian Polytechnic University, Dalian,

China

Full list of author information is available at the end of the article
}

environment $[3,4]$. Generally, the $\mathrm{Cr}$ is a necessity in production of numerous industrial products, including rubbers, fungicides, ceramics, pigments, inks, and corrosion inhibitors, etc. [5, 6]. In addition, it is important to plants and animals for the metabolism of sugar and fat as the Cr (III) concentration is below $50 \mu \mathrm{g} / \mathrm{L}$. However, the long exposure to $\mathrm{Cr}$ (III) ions with high concentration will lead to cancer and allergic skin reactions. As compared to $\mathrm{Cr}$ (III) ions, $\mathrm{Cr}$ (VI) ions are much more toxic (about 300 times) due to their oxidation potential and penetration in the tissue, which can cause the human lung fibroblasts to undergo apoptosis $[7,8]$. Hence, considering the high toxicity, the remove and recycle of $\mathrm{Cr}$ ions from industrial effluents before discharging into the environment is particularly important. 
In general, the classical available methods for purification of wastewater with $\mathrm{Cr}$ ions include adsorption, coagulation, ion exchange, electro-chemical precipitation, membrane technologies and reverse osmosis, etc. [811]. However, these methods have significant disadvantages and are not completely suitable for the treatment of tannery wastewater. Among the technologies, the adsorption by various adsorbents is regarded as one of the most promising methods, since it is handy and highefficiency for the removal of the contaminant with relative lower concentration (often below $50 \mathrm{mg} / \mathrm{L}$ ), which is particularly significant for deep purification of wastewater in the industry. In the last decades, many attempts have been made to adsorb heavy metal ions by activated carbon from effluent, which is an effective material for removing $\mathrm{Cr}$ ions. However, the high cost of commercial activated carbon limits its wide application in biosorption. Consequently, new strategies for $\mathrm{Cr}$ (III)/Cr (VI) adsorption have proposed with both low-cost and an excellent adsorption capacity. Therefore, various other nature materials including the chitosan, fly ash, coal, zeolites, cellulose, and lignin have been studied for the removal of $\mathrm{Cr}$ ions [12].

In recent years, lignins have been drawn great attention for adsorbing different heavy metal ions from water because of the abundance, low cost and biodegradability, as well as the existence of effective adsorption sites in macromolecules. To evaluate the absorbability of lignin to $\mathrm{Cr}$ ions, the lignin separated from pulping black liquor was directly used to remove $\mathrm{Cr}$ ions and the maximum adsorption capacity was $17.97 \mathrm{mg} / \mathrm{g}$ [13]. Recently, Nair et al. [14] investigated the chitosan-alkali lignin composites for adsorbing $\mathrm{Cr}$ (VI) and the result indicated that $95 \%$ of $\mathrm{Cr}$ (VI) ions could be removed under the given conditions. Similarly, Song et al. [15] prepared a magnetic lignin composite for adsorption of $\mathrm{Cr}$ (VI). Recently, the waterresistant lignin/PVA blend fibers were also fabricated to remove $\mathrm{Cr}(\mathrm{VI})$ ions, and obtained an excellent absorbability of $350.87 \mathrm{mg} / \mathrm{g}$, meanwhile presented the promising regeneration [16]. In these studies, due to the various structural characteristics and functional groups, lignin obtained from different biomass species and extraction methods showed diverse adsorption capacities and adsorption mechanisms. Actually, the inherent complex structure of lignin macromolecules has been proved to be an important factor in not only adsorption but also other applications, such as dispersant, polyurethane, and various carbon materials. Therefore, the understanding of chemical structure and extraction process of lignin, as well as the modification methods are particularly important.

Every year, over 50 million tons of industrial lignins were produced from pulping and bio-refinery processes, but only an estimated $2-5 \%$ of the extracted lignins were developed into specialty products, but the others were directly combusted to provide low value-added fuels. This underutilization of industrial lignin inspires the researchers to both understand the physicochemical structure information of lignin and engineer the promising lignin-based materials. Therefore, in this paper, the extraction processes and the characterization techniques of lignin from lignocellulosic biomass are first discussed, which is crucial to their further modification and utilization. Subsequently, the modification and functional groups present in lignin are briefly overviewed. Finally, the lignin adsorption of chromium ions from wastewater is discussed in detail.

\section{Fractionation and characterization of lignin from lignocellulosic biomass \\ 2.1 Lignin extraction}

Many processes have been developed for extraction of lignin from wood and non-wood lignocellulose. According to the different purposes of extraction, it can be mainly divided into two different kinds: one is used in an analytical scale, mainly for structural analysis, and another is used at an industrial level. In this part, both the analytical scale and the industrial level will be comparatively discussed.

In view of the diversity of lignin structure, which is highly dependent on the lignocellulosic biomass and extraction methods, many processes have been investigate to extract lignin with chemical structure to be as complete as possible. According to the previous research, many kinds of native lignins have been separated through different solvents, such as DMSO and dioxane.

\subsubsection{Milled wood lignin (MWL)}

Milled wood lignin (MWL) is identified as one of the most representative samples, which is fractionated based on the classical way that first developed by Björkman [17]. For the separation of MWL, lignocellulose was first reduced into fine particles (less than $0.8 \mathrm{~mm}$ ) by ball milling. Afterwards, ball-milled wood was treated through $96 \%$ of 1,4 dioxane with a ratio of 1: 20 (wood: 1, 4-dioxane: $\mathrm{g} / \mathrm{mL}$ ) at normal temperature, whereas only $5-20 \%$ of lignin can be extracted through this method. Afterwards, some modified methods were successively proposed to increase the yield of MWL. For instance, Sun et al. [18] extracted the MWL using the $80 \%$ dioxane with a ratio of 1: 20 (wood: 1, 4-dioxane: $\mathrm{g} / \mathrm{mL}$ ) at $50^{\circ} \mathrm{C}$ in dark for $12 \mathrm{~h}$. In addition, the increasing of milling time also improved the yield of MWL $[19,20]$. Nevertheless, most of the lignin is still retained in the biomass and cannot be easily extracted as a native lignin.

\subsubsection{Cellulolytic enzyme lignin (CEL)}

CEL is also considered as a desirable sample to characterize the structure of lignin, which was similar to 
that of MWL. The extraction of CEL was mainly divided into three stages: (i) the lignocellulose was ball milled for about $5 \mathrm{~h}$; (ii) the ball milled lignocellulose is then hydrolyzed by composite enzymes of cellulose and hemicelluloses to digest carbohydrates into monosaccharides; and (iii) the solids obtained after the enzyme hydrolysis are then treated by $96 \%$ of dioxane to extract CEL, and the detailed processes are same as the extraction of MWL [21, 22]. Although the structural features of CEL were similar to those of MWL, the yield of CEL was apparently enhanced. Therefore, the CEL is regarded as the more representative lignin to elucidate its nature structure. Recently, to improve the yield of native lignin, Sun et al. [23] prepared the regenerated cellulolytic enzyme lignin (RCEL) from hard wood through a modified CEL preparing process, which was according to DMSO/ [Emin] OAc dissolution and regeneration process. The result showed that the yield of RCEL could reach up to $85.3 \%$, and the structural features, e.g. molecular weight, constitutes ( $\mathrm{S}$ and $\mathrm{G})$, and major lignin linkages ( $\beta-O-4$, $\beta-5$ and $\beta-\beta)$, were similar to those of CEL. Hence, Sun et al. [23] regarded RCEL was also a "model sample" to study lignin structure.

\subsubsection{Enzymatic mild acidolysis lignin (EMAL)}

Enzymatic mild acidolysis lignin (EMAL) is another kind of lignin samples that extracted from milled wood through composite processing based on mild enzymatic and acid hydrolysis [24]. The milled lignocellulosic biomass is first treated by cellulolytic enzymes to remove most carbohydrates and then with mild acid to hydrolyze the reserving lignin-carbohydrate bonds, hence producing a native lignin with a high yield $(2-5$ times higher than CEL or MWL), molecular weight, and purity.

\subsubsection{Double enzymatic lignin (DEL)}

Recently, a combination of double ball-milling and enzymatic hydrolysis process has been presented by Sun and co-workers [25-27]. During the preparation process of DEL, the lignocellulose biomass was first milled at $450 \mathrm{rpm}$ for $5 \mathrm{~h}$. The ball-milled biomass was then enzyme hydrolyzed and the recovered residual lignin was successively subjected to ball-milling $(450 \mathrm{rpm}, 2 \mathrm{~h}$ ) and enzymatic hydrolysis to produce DEL. As compared to the CEL, the DEL samples presented higher yield (5-10 folds) and much more $\beta-O-4$ linkages. Therefore, the extracted DEL can also be considered as the "model lignin" for studying the chemical structural characteristics of whole lignin in different lignocellulosic biomass.

The industrial processes to separate lignin involve various pulping and biorefinery processes. For the pulping process, Kraft and soda processes are widely used to prepare paper pulp and vast industrial lignin was produced as a by-product [28]. The basis of paper pulp processes is to separate the lignin into solution, mainly aqueous alkali, and obtain a cellulose pulp with a high purity. For the biorefinery, the lignin was mainly obtained as a solid residue, and the cellulose and hemicelluloses were transformed into the corresponding products, such as bioethanol and oligosaccharides, etc. In general, the industrial lignins have much more condensation linkages and units as compared to the native lignin, which partly impeded their utilization for industrial.

\subsubsection{Soda lignin (SL)}

The soda pulping is one of the most important techniques for producing pulp (5-10 kt/year) from nonwood lignocellulose, such as straw, sugarcane bagasse, kenaf, and sisal $[29,30]$. In some case, non-wood lignocellulose is usually pretreated by hot water $\left(70-80^{\circ} \mathrm{C}, 2\right.$ h) before the soda pulping with a solid-to-liquid ratio of 1: $10(\mathrm{w} / \mathrm{w})$ and a small amount of low molecular weight lignin fractions were separated and dissolved in water [31]. The separated solids were then treated with 13$16 \%$ weight of sodium hydroxide solution at $140-170^{\circ} \mathrm{C}$. After that, the compounds were filtrated to separate black liquor and crud pulp. The black liquor was acidified to $\mathrm{pH}=2$ by sulfuric acid to precipitate the soda lignin. In addition, the anthraquinone ( $\mathrm{AQ}$ ) was usually used as a catalyzer in some soda pulping process to protect the hemicelluloses and dissolve lignin as much as possible. Meanwhile, the addition of AQ improved the cleavage of $\beta-O-4$ linkages and prevented the condensation of the produced lignin molecules. Therefore, the soda lignin has much lower molecular weights (1000$4000 \mathrm{Da})$ and higher contents of phenolic hydroxyl groups as compared to other industrial lignin fractions [32]. Additionally, the soda lignin fractions possess no sulfur, which can be deemed as a promising material for the production of high-value products.

\subsubsection{Kraft lignin}

Kraft pulping process is the most common technique developed in processing biomass, which produces approximately $90 \mathrm{kt} /$ year of Kraft lignin (KL) fractions. The lignin is dissolved in alkaline solution during the Kraft pulping process, which is similar to soda pulping process but with the addition of $\mathrm{Na}_{2} \mathrm{~S}$. In general, $\mathrm{KL}$ contains abundant phenolic hydroxyl groups those result from the depolymerization by cleavage of $\alpha-O-4$ and $\beta$ $O-4$ linkages. In addition, the condensation increased the molecular weights of KL by the formation of C-C linkages, thus the molecular weights were between 1000 and $15,000 \mathrm{Da}[33,34]$. However, the sulfur groups (low than $3 \%$ by wt) in lignin resulted from the Kraft pulping process restricted the industrial utilization of KL. Thus, only $2-5 \% \mathrm{KL}$ was applied to specialty products, such as bio-adsorbent for removing heavy metal. 


\subsubsection{Lignosulfonates (LS)}

Lignosulfonates are the most important commercially available lignin (100 kt/year), which are generated as a by-product from the sulfite pulping process. This process is usually conducted at the temperatures of $120-180^{\circ} \mathrm{C}$ for $1-5 \mathrm{~h}$ [35]. During the pulping process, between 4 and $8 \%$ of sulfur groups are grafted onto the aromatic carbon of lignin in the form of sulfonate groups, which makes them water-soluble. Due to the acid conditions of sulfite pulping process, most $\beta-O-4$ and $\alpha-O-4$ linkages were broken, which led to some condensed structure. However, as compared to KL, LS fractions exhibit higher molecular weights ranging between 1000 and 50,000 Da [29, 36, 37]. Especially, LS presents excellent surfactant properties that can be applied in several industries, e.g. surfactant, dispersant and water reducer in concrete. Meanwhile, the grafted sulfur groups are regarded as the effective sites for adsorbing heavy metals.

\subsubsection{Organosolv lignin (OSL)}

Organosolv lignin is extracted from lignocellulose by various organic chemicals, such as ethanol, methanol, isopropanol, acetone, formic acid, and acetic acid, with or without the addition of an acid-based catalyst [3842]. The organosolv process is performed through using the organic solvent aqueous solution to extract the lignin and hemicelluloses at temperatures between 120 and $220^{\circ} \mathrm{C}$ for $0.5-2 \mathrm{~h}$. The dissolved hemicelluloses and lignin can be recovered by precipitating in 3 volumes of ethanol and 10 volumes of acid water $(\mathrm{pH}=2$, adjusted by $\mathrm{HCl}$ ), respectively. During the delignification process, the linkages between lignin and polysaccharides are broken, but most $\beta-O-4$ linkages can be reserved. Meanwhile, the generation of condensed structure in lignin is quiet restricted due to the presence of organic solvents, and the molecular weights ranged from 500 to $5000 \mathrm{Da}$. Therefore, the structure features of organosolv lignin are more similar to those of native lignin (MWL, CEL, and EMAL, etc.). In addition, the OSL has a high purity, low ash, and no sulfur as compared to other industrial lignins. Furthermore, the organosolv extraction process is basically eco-friendly as only the water and organic solvents are used as extraction reagents. However, it can cause the equipment to be serious corroded and the quality of the pulp to be satisfactory, the organosolv process has not been widely applied and the production of OSL is limited.

\subsection{Chemical composition and characterization of lignin 2.2.1 Chemical composition of lignin}

Lignin, the main renewable source of aromatic structures, accounts for $15-30 \%$ dry weight of biomass desponding on the biomass species, growing environment and ages, as summarized in Table $1[26,27,43,44]$. In primary and secondary cell walls, the lignin is normally linking with hemicellulose around the cellulose bundles [45], and is usually combining with the carbohydrate/cellulose by covalent bonding (Fig. 1), which plays important roles in resistance against microbial attack and transportation of water and nutrients. Lignin is mainly composed of three units: syringyl $(S)$, guaiacyl $(\mathrm{G})$, and p-hydroxyphenyl $(\mathrm{H})$ units linked by arylether ( $\beta-O-4,4-O-5$ and $\alpha-O-4$,$) and$ $C-C(\beta-\beta, \beta-1, \beta-5$ and $5-5)$ bonds. The possible structure of the nature lignin from Eucalyptus species is shown in Fig. 2, which was proposed by Sun et al. [26] according to the $\mathrm{S} / \mathrm{G}$ ratios and different linkages contents. As observed in Fig. 2, the lignin showed branched structure. The functional groups such as phenolic and carboxylic associated with the lignin molecules led to lignin as a high practical polymer in industry utilization. For example, these functional groups could be regarded as the absorption sites for various metal ions. Especially, the branched structure of lignin has strong binding interactions with the chromium metal ions, which would favor the removal of the contaminant from the wastewater.

In plant cells, lignin is biosynthesized from three primary phenylpropane monomers of 4-hydroxy-3,5dimethoxycinnamyl (sinapyl, S), 4-hydroxy-3-methoxycinnamyl (coniferyl, G) alcohol and 4-hydroxycinnamyl (p-coumaryl, $\mathrm{H}$ ) alcohol by the random polymerization [46, 47]. General, guaiacyl unit $(92-95 \%)$ is the primary type of softwood lignin, while the hardwood lignin is constituted of syringyl and guaiacyl with approximately two equal amounts. The components of lignin from grass are complex since it possesses all three units. Beside the basic structural unit of SGH-type, other structures such as ferulate (FA), p-coumarate (PCE), and cinnamyl aldehyde end-groups (J), etc. were also found in grass lignin $[48,49]$. In lignocellulose biomass, these structural units are linked by various alkyl ether linkages and $\mathrm{C}-\mathrm{C}$ linkages, and the primary one is $\beta-O-4$ bonds. The compositions and structures of lignin from several different species and extraction methods have been characterized through many methods those mainly divide

Table 1 Composition of cellulose, hemicelluloses, and lignin in various biomass

\begin{tabular}{lllll}
\hline \multirow{2}{*}{ Biomass } & \multicolumn{3}{l}{ Component (\% dry weight) } & Reference \\
\cline { 2 - 4 } & Cellulose & Hemicelluloses & Lignin & \\
\hline Monterey pine & 44 & 21 & 26 & {$[44]$} \\
E. grandis & 41 & 17 & 29 & {$[18]$} \\
Populus tomentosa Carr & 46 & 29 & 23 & {$[23]$} \\
Miscanthus X Giganteus & 37 & 36 & 25 & {$[43]$} \\
Switchgrass & 38 & 32 & 26 & {$[27]$} \\
Hybrid Pennisetum & 42 & 30 & 24 & {$[27]$} \\
\hline
\end{tabular}




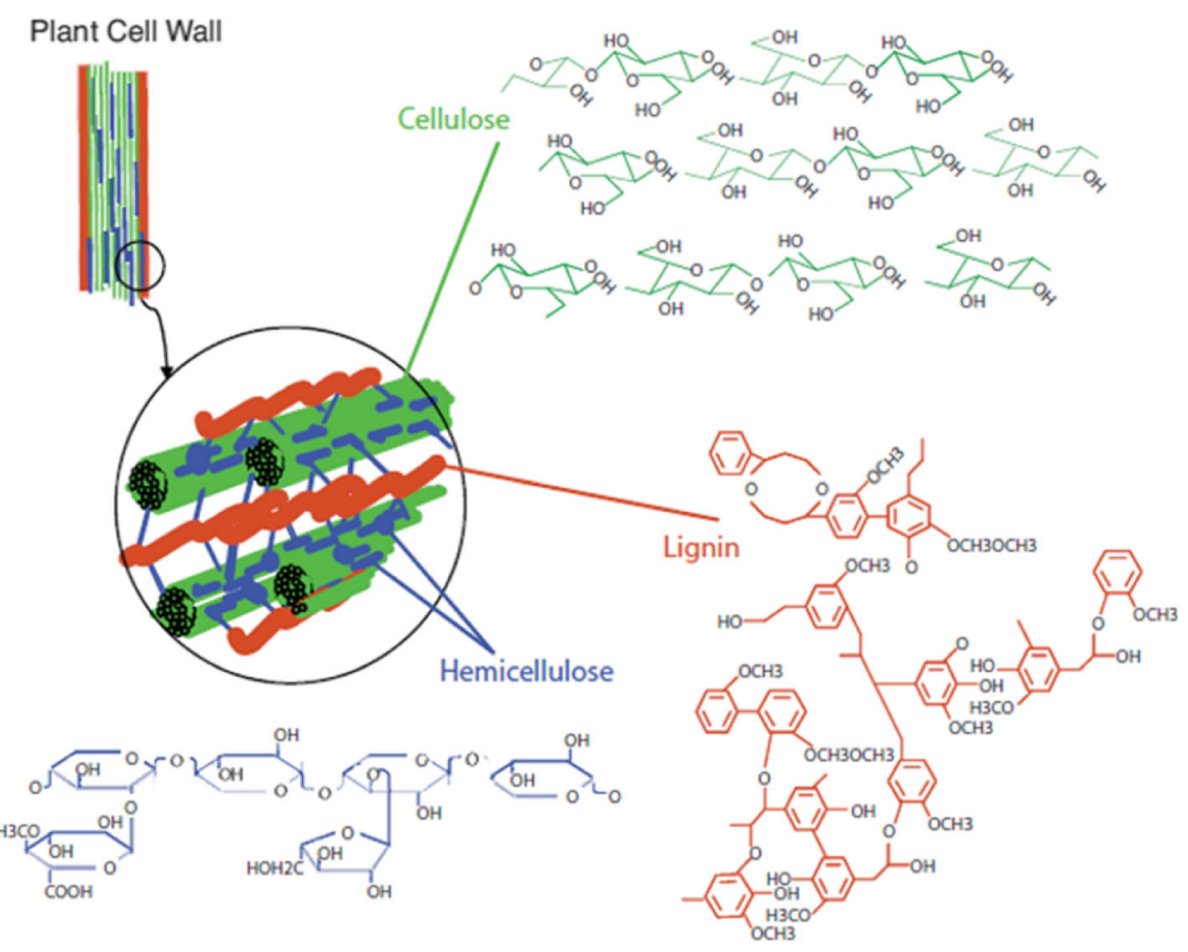

Fig. 1 Hierarchical structure of lignocellulosic biomass

into solid-state and solution-state methodology. However, it is significant to note that not any lignin structures have been fully elucidated due to the nature diversity of the lignin and its derivatives.

\subsubsection{Solid-state methodology for the structural characterization of lignin}

Solid-state methodology is a facile method to characterize the physicochemical properties of the isolated lignin but yields limited internal information. The typical solid-state characterization methods including FTIR spectroscopy, cross-polarization/magic angle (CP/MAS) ${ }^{13} \mathrm{C}$ NMR spectra, scanning electron microscope (SEM), spinning Raman spectroscopy, and gas chromatography-mass spectrometry $(\mathrm{GC}-\mathrm{MS})$. In addition, the thermodynamic properties characteristic of lignin are mainly thermogravimetry (TGA) and thermodynamic properties differential scanning calorimetry (DSC). Here, the major technique for the structural characterization of lignin will be briefly overview in this study.

2.2.2.1 FTIR spectroscopy analysis Among the solidstate methodology, the FTIR spectroscopy and thermal characterization techniques are two common methods since they are their facile, accessible, and directly informative. In the past decades, the FTIR spectroscopy is constantly improved that it can well detect the functional groups in lignin, e.g. hydroxyl (phenolic and aliphatic hydroxyl), carboxyl, methoxyl, carbonyl, and aromatic and aliphatic $\mathrm{C}-\mathrm{H}$, as well as distinguish the lignin units [50-52]. Faix et al., [50, 51] focused on the isolation and comparative characterization of the functional groups in MWL from grass and the characteristic peaks were assigned.

2.2.2.2 Thermogravimetric analysis It is well known that the thermal analysis is an important technique to study the thermodynamic properties, mainly including glass transition temperature $(\mathrm{Tg})$ and decomposition temperature $(\mathrm{Td})$, which provides important information to prepare the lignin-based materials with given properties. Nevertheless, the Tg of lignin is closely related to its structural features, such as molecular weights, intermolecular linkages, and functional groups, which depended on the lignocellulose species and extraction methods. To study the influence of extraction methods on the thermal degradation characteristics, the alkali lignins (ALs) and organic solvent lignins (OLs, extracted by benzyl alcohol, dioxane, and ethanol) were prepared in the study of Tao [53]. The result showed that AL presented a retarded pyrolysis phenomenon and a higher char yield (45.9\%) than those of the OLs (30.9-32.7\%), which suggested that the alkali separation process modified the lignin and was favor to the char formation. Besides the preparation methods, the techniques and parameters during the thermogravimetric detection process are also 


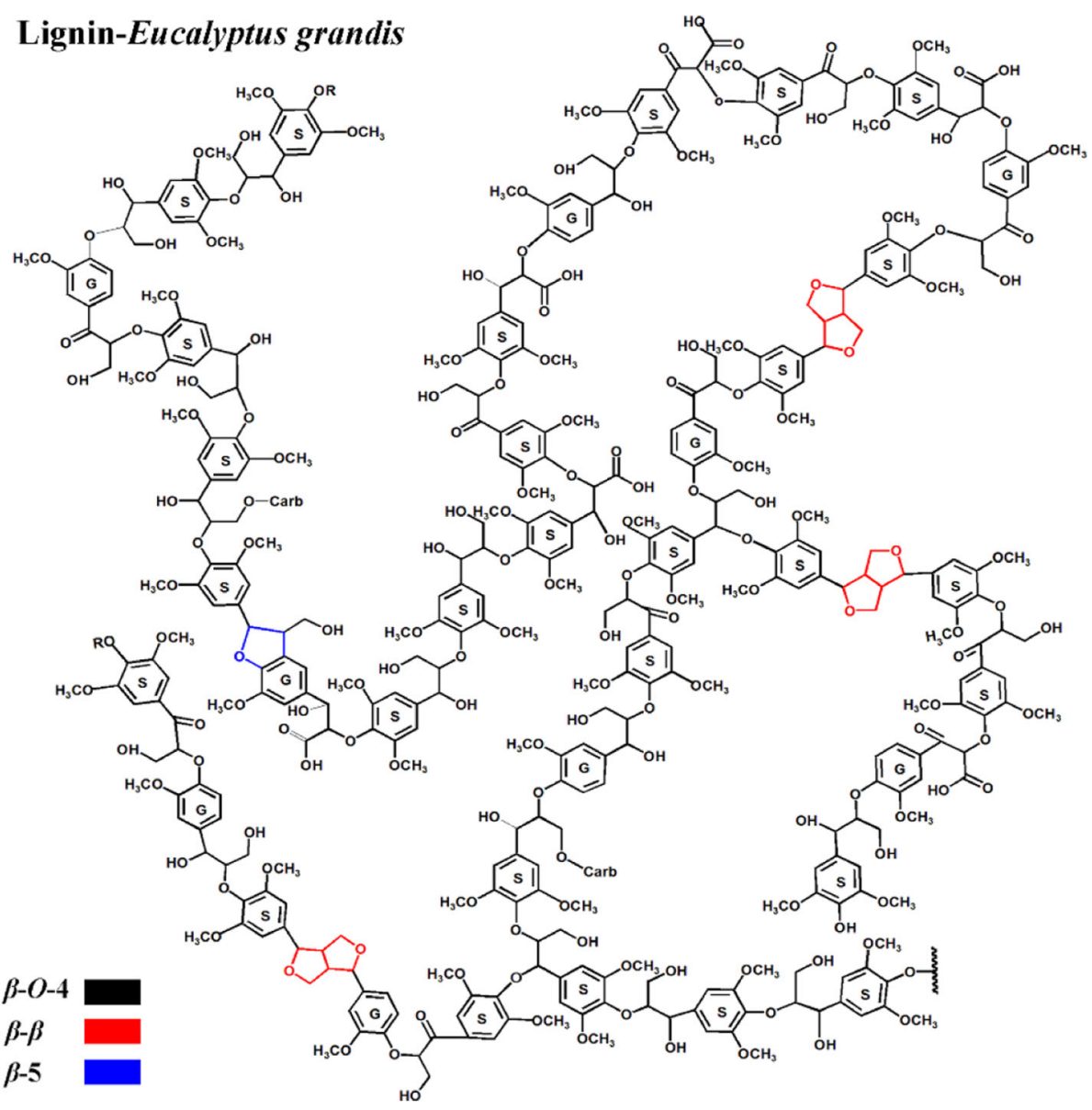

Fig. 2 Structural of Eucalyptus lignin with the main units and linkages. Reprinted with permission from ref. [18]

contribute to the differences of obtained results. Yang et al. [54] studied the influence of the heating rates on the thermogravimetric character of EMAL from wheat straw. The thermal decomposition rate enhanced over 200$500^{\circ} \mathrm{C}$ with the heating rate increased from 10 to $50^{\circ} \mathrm{C} /$ min and the temperatures of the maximum loss of the mass peaks shifting to a high temperature area. Meanwhile, the mass peaks belonging to the maximum loss of lignin shifting towards a high temperature area. Kubo et al. [55] investigated the thermal decomposition of three different kinds of industrial lignin (including hardwood kraft lignin: HKL, softwood kraft lignin: SKL, and organosolv lignin: OL) by the TA-Instrument TA-Q500 TGA and non-modulated Hi-Res TGA experiment, respectively. The result obtained from TA-Instrument TA-Q500 TGA method showed the main decomposition temperature for SKL, HKL, and OL was 366,345 , and $347^{\circ} \mathrm{C}$, respectively. However, the main decomposition temperature of the obtained by another method was 345,347 , and $366^{\circ} \mathrm{C}$ for OL, HKL, and SKL, respectively, which were lower than those detected by the traditional TGA methods. The reasons for this diversity were mainly thanks to the slower heating rate and the improved resolution of the $\mathrm{Hi}-\mathrm{Res}$ TGA. However, the shoulder at around $300{ }^{\circ} \mathrm{C}$ on the DTGA curves still overlap with the main decomposition peak in the Hi-Res TGA. Therefore, the MTGA analysis was then developed through the Hi-Res TGA at a slow heating rate of $2{ }^{\circ} \mathrm{C} / \mathrm{min}$ and the broad lower temperature peak in the MTGA curve is clearly resolved. Therefore, in the study of thermodynamic properties of lignin, a combination of technologies should be used and compared.

\subsubsection{Solution-state characterization methodology for the structural characterization of lignin}

Solution-state characterization methods such as gel permeation chromatography (GPC), high-performance anion-exchange chromatography (HPAEC), UV spectroscopy, solution-state NMR, and some chemical degradation methods (acidolysis, hydrogenolysis, oxidation, derivatization, and DFRC) have been used to investigate the composition and structural features of the extracted lignin. Among the solution-state characterization methods, the solution-state NMR, mainly including ${ }^{1} \mathrm{H},{ }^{13} \mathrm{C},{ }^{31} \mathrm{P}$, and 2D-HSQC spectroscopies, is a comprehensive and reliable 
technique in the characterization of the chemical structure of lignin.

2.2.3.1 ${ }^{1} \mathrm{H}$-NMR spectra analysis In the solution-state NMR, ${ }^{1} \mathrm{H}$-NMR was the first used spectroscopy for lignin characterization. In the ${ }^{1} \mathrm{H}-\mathrm{NMR}$ spectroscopy, the different hydroxyl groups of lignin can be quantitated by measuring the acetylated lignin. In the earlier study, Lundquist et al. [56] found the signals of formyl groups in the ${ }^{1} \mathrm{H}$-NMR spectroscopy of acetylated MWL from spruce, which was obtained using a $270 \mathrm{MHz}$ instrument. Afterwards, more available structural information was constantly found in the study of the ${ }^{1} \mathrm{H}-\mathrm{NMR}$ spectrum. As the development, it cannot just examine the rough signals of acetylated lignin derivatives, but provide some important information about the main functionalities of different lignins, including hydroxyl, methoxyl, $\mathrm{CH}_{2}, \mathrm{CH}_{3}$, and carboxylic acids groups, as well as the structural units and linkages [57]. Specifically, the peaks at 2.01 and $2.28 \mathrm{ppm}$ are assigned to acetyl groups and the integration suggests a total ratio of acetyl groups to phenylpropane unite. In addition, the peaks at $2.62,5.49,6.06 \mathrm{ppm}$ are due to $\mathrm{H}_{\alpha}$ in $\beta-\beta, \beta-5$, and $\beta-O-$ 4 structure, respectively. Especially, the integration of the peak at $6.06 \mathrm{ppm}$ indicates the proportion of the side chains those involved in $\beta-O-4$ structure. Apart from the side chains, the signals attributed to aromatic groups are mainly distributed at $6.00-8.00 \mathrm{ppm}$. However, the signals of ${ }^{1} \mathrm{H}$ NMR from lignin are somewhat overlapped, which cannot be clearly vested and quantitative. Therefore, with the development of NMR techniques, ${ }^{31} \mathrm{P}-\mathrm{NMR},{ }^{13} \mathrm{C}$ NMR, and 2D-HSQC are also widely used to accurately study the detailed information of lignin structure and quantitate the functional groups and linkages in lignin.

2.2.3.2 ${ }^{31} \mathrm{P}$ NMR The quantitation of hydroxyls groups in lignin mainly through the phosphating reaction between hydroxyl groups and phosphating reagent (the most common reagent is 2-chloro-4,4,5,5-tetramethyl-1, 3,2-dioxaphospholane, i.e., TMDP) in an organic condition, such as pyridine and chloroform [58-60]. Generally, $20 \mathrm{mg}$ of lignin was dissolved in a mixed organic solvent of anhydrous pyridine and deuterated chloroform $(500 \mu \mathrm{L}, 1.6,1, \mathrm{v} / \mathrm{v}$, named as $\mathrm{A})$. Then, $100 \mu \mathrm{L}$ of cyclohexanol $(10.85 \mathrm{mg} / \mathrm{mL}$ in A solvent) as an internal standard and $100 \mu \mathrm{L}$ of chromium (III) acetylacetonate solution $(5 \mathrm{mg} / \mathrm{mL}$ in A solvent) as the relaxation reagent was successively added into the above lignin solvent. After the lignin was completely dissolved, $100 \mu \mathrm{L}$ of TMDP was added into the mixture and kept about 10 min to ensure the reaction was completed, and the phosphorylation of hydroxyl groups in lignin is shown in Fig. 3 [60]. This technique can be particularly quantified the primary and secondary hydroxyl groups (Al-OH), syringyl hydroxyls $(\mathrm{S}-\mathrm{OH})$, guaiacyl hydroxyls $(\mathrm{G}-\mathrm{OH})$, hydroxyphenyl hydroxyl (H-OH), as well as the carboxylic $(\mathrm{COOH})$ groups according to different chemical shifts of hydroxyl groups in lignin, as shown in Fig. 4. In detail, the signal belonging to internal standard is distributed between 145.32 to $144.90 \mathrm{ppm}$. The signal at $143.20-142.17,140.17-138.79$, and $138.40-137.10 \mathrm{ppm}$ is uncondensed S-type, G-type, $\mathrm{H}$-type $\mathrm{OH}$ of lignin, respectively. In addition, the condensed S-type and G-type $\mathrm{OH}$ (mainly $\mathrm{C}_{5}$ substituted) is distributed at 144.50 $134.20,142.17-141.42 \mathrm{ppm}$, respectively. Usually, a weak peak according to carboxylic $\mathrm{OH}$ groups is observed at 135.50-134.20.

Up to now, ${ }^{31} \mathrm{P}-\mathrm{NMR}$ spectrum has been widely applied in the study of the variation of hydroxyl groups in lignin, and is proved to be a useful technique to figure out the variations of structure features of lignin resulting from different extraction processes and biomass species. For instance, Guerra et al. [61] measured and compared the hydroxyl groups of MWL, EMAL, and CEL through the above quantitative ${ }^{31} \mathrm{P}$ NMR system. The result indicated that the total and condensed contents phenolic hydroxyls of MWL from Douglas fir, White fir, Redwood, Eucalyptus, and Pine were all higher than those in the corresponding CEL and EMAL, which suggested that the lignin with phenolic-rich structure was more preferentially and easily extracted in isolation process of MWL. The result was consistent with the report of Holtman et al. [62] and Yuan et al. [63].

For the different phenolic hydroxyl types, the lignin extracted from different lignocellulosic biomass shows significant differences. Yuan et al. [61] studied the lignin from Populus tomentosa Carr and the ${ }^{31} \mathrm{P}$-NMR result showed that the G- and S-type phenolic hydroxyls of AL was 0.36 and $0.28 \mathrm{mmol} / \mathrm{g}$, respectively. Meanwhile, 0.02 $\mathrm{mmol} / \mathrm{g}$ of $\mathrm{H}$-type phenolic hydroxyls were detected, which was consistent with the previous report [64]. For the condensation structures, 0.1 and $0.06 \mathrm{mmol} / \mathrm{g}$ of Sand G- type 5-substituted phenolic hydroxyls were also detected, respectively. In case of softwood, a dominate amount of G-type hydroxyl $(0.20-1.22 \mathrm{mmol} / \mathrm{g})$ and a small content of H-type hydroxyls $(0.01-0.12 \mathrm{mmol} / \mathrm{g})$ were found in native lignin $[60,65,66]$. However, as compared to the native lignin from hardwood and softwood, the lignin from grass had more $\mathrm{H}$-type hydroxyls $(0.32-0.82 \mathrm{mmol} / \mathrm{g})$ [27].

The reports showed that ${ }^{31} \mathrm{P}-\mathrm{NMR}$ has become a widely used method in quantitation of hydroxyls in lignin, whereas the lignin should be dissolved in organic solvents completely, especially in anhydrous pyridine and deuterated chloroform. However, due to the poor solubility of some industrial lignin samples, such as lignosulfonates, in the commonly used solvent 


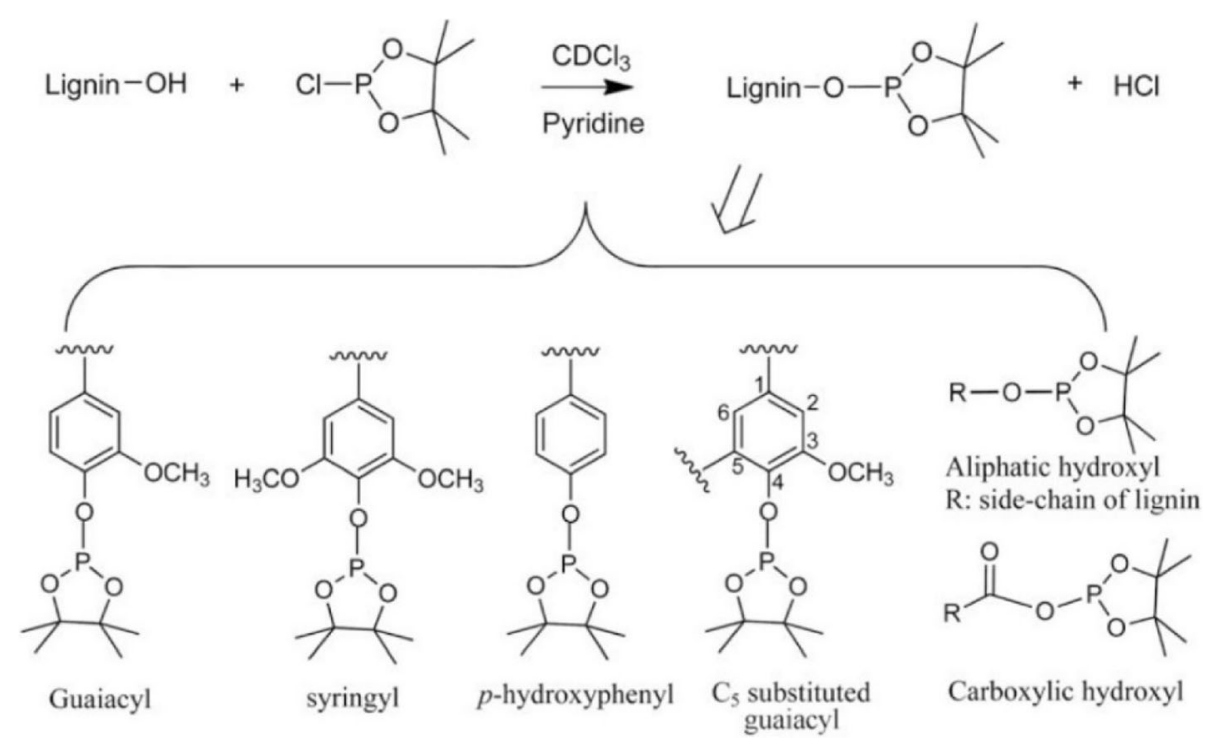

Fig. 3 Phosphitylation of hydroxyl groups in lignin structural units with 2-chloro-4,4,5,5-tetramethyl-1,3,2-dioxaphospholane (TMDP). Reprinted with permission from ref. [60]

systems, the analysis of hydroxyl groups by this method is rather difficult. To overcome this limitation, some research has used different derivatization steps prior to NMR analysis. Recently, Stücker et al. [67] proposed a practicable method for quantitative studying the hydroxyl groups in lignosulfonates (LS). LS was firstly added into lignosulfonic acids through ion exchange and then freeze-drying. After that, LS was dissolved into DMF/DMF- $\mathrm{d}_{7} /$ pyridine (4.5: 1: 1 ; v/v) with endo-N-hydroxy-5-norbornene-2,3-dicarboxylic acid imide as an internal standard, and TMDP as the derivatization reagent. The results obtained through this novel solvent system were compared with those detected via the conventional technique with different internal standards to assess its reliability. In general, the signal shape and intensity of aromatic $\mathrm{OH}$ groups obtained by the novel solvent showed good consistency with that detected by traditional solvent systems. However, for the lignosulfonic acids, the intensity of spectra obtained from the novel solvent system were lower than that from $\mathrm{CDCl}_{3} /$ pyridine system, while led overall to higher hydroxyl contents.

2.2.3.3 Two-dimensional HSQC NMR technique The two-dimensional heteronuclear single quantum coherence (2D-HSQC) NMR technology is one of the most popular and powerful tool for the lignin characterization, which enables reliable assignments of proton and carbon nuclei signals in lignin macromolecules. Based on the great contributions made by Ralph and other workers [46-48, 68-70], the ${ }^{1} \mathrm{H}_{-}{ }^{13} \mathrm{C}$ correlation NMR technology has been considered to be a very efficient tool for not only structural identification but also calculation of the

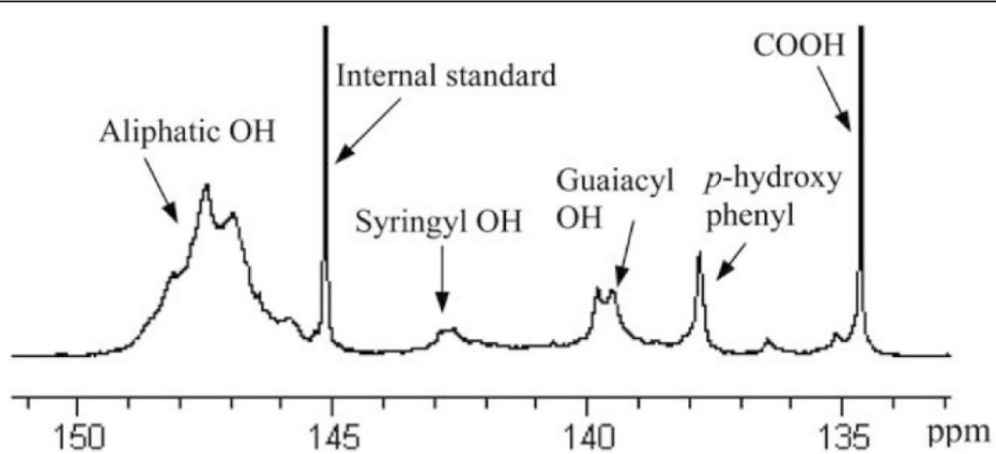

Fig. 4 A typical ${ }^{31}$ P NMR spectrum of a switchgrass ball-milled lignin derivatized with TMDP using cyclohexanol as internal standard. Reprinted with permission from ref. [60] 
relative abundance of linkages and monolignol in native and industrial lignin. The typical 2D-HSQC spectra of DEL from Switchgrass and the corresponding major substructures are shown in Fig. 5 [27]. In detail, the main structural units of SGH-type and the main bonds of $\beta-5$, $\beta-\beta$ and $\beta-O-4$ were found in Switchgrass lignin. In addition, the strong signals of ferulates (FA) and pcoumarates (PCE) were also found in the 2D-HSQC NMR spectrum of grass lignin, which was consistent with the previous reports $[27,71,72]$. In general, the signals intensities of FA and PCE were decreased during the pretreatment. Recently, according to the recent reports by Yue [73], the 4-O-5 linked structures were clearly identified and quantified in softwood lignin by 2D-HSQC NMR technology.

Besides the qualitative assignment, quantitative analysis of the lignin unit and linkages is also an important aspect for lignin structural characterization. According to previous studies, "semi-quantitative and quantitative" methods were adopted in the quantitative of lignin structure, which depended on the method without internal standard (IS) and with aromatic units as IS, respectively [74-77]. In a semi-quantitative method, the calculation formula of relative abundance of linkages in lignin is described as follows:

$$
\mathrm{I}_{\mathrm{X}} \%=\mathrm{I}_{\mathrm{X}} /\left(\mathrm{I}_{\mathrm{A}}+\mathrm{I}_{\mathrm{B}}+\mathrm{I}_{\mathrm{C}}+\mathrm{I}_{\mathrm{D}}\right) \times 100 \% .
$$

Where $I_{A}, I_{B}, I_{C}$, and $I_{D}$ are the integral values of $\alpha$ position of $\beta-O-4$ (A), $\beta-\beta$ (B), $\beta-5$ (C), and $\beta-1$ (D), respectively.

However, the results obtained through this formula are not able to compare the absolute differences between the lignin samples from different plant species. Therefore, the quantitative method based on the aromatic units as IS was usually used to calculate the absolute content of lignin structure. In the quantitative method, a cluster of signals that represents C9 units was used to be IS, which was different on the basis of diverse lignin samples.

$$
\begin{aligned}
\mathrm{IC} 9 \text { units }= & 0.5 \mathrm{IG}_{2}(\text { softwood lignin }) \\
\mathrm{IC} 9 \text { units }= & \left.0.5 \mathrm{IS}_{2,6}+\mathrm{IG}_{2} \text { (hardwood lignin }\right) \\
\mathrm{IC} 9 \text { units }= & 0.5 \mathrm{IS}_{2,6}+\mathrm{IG}_{2} \\
& \left.+0.5 \mathrm{IH}_{2,6} \text { (grass lignin }\right)
\end{aligned}
$$

Where IC9 represents the integral value of the aromatic ring. $\mathrm{IS}_{2,6}, \mathrm{IG}_{2}$ and $\mathrm{IH}_{2,6}$ is the integration of $\mathrm{S}_{2,6}$ $\left(S_{2,6}+S_{2,6}^{\prime}\right), G_{2}$ and $H_{2,6}$, respectively. Based on the internal standard (IC9), the amount of lignin units and linkages could be achieved by the following formula:
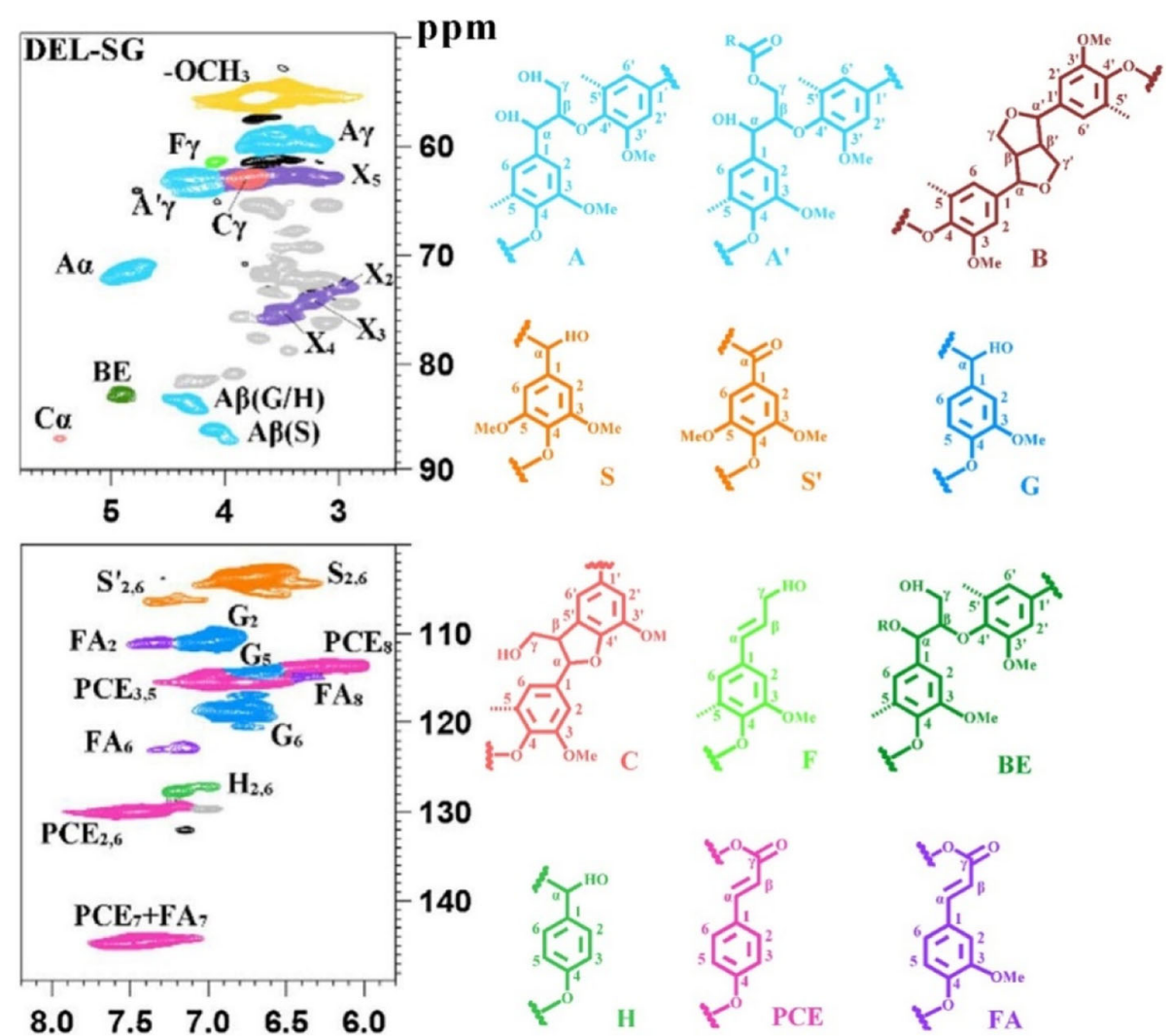

130

140
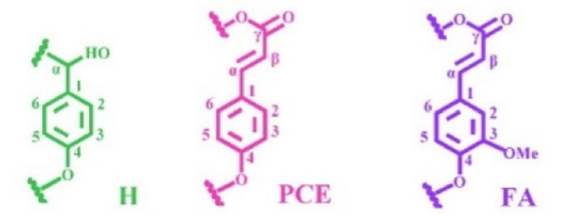

Fig. 5 The typical 2D-HSQC spectra of DEL from Switchgrass and the corresponding major substructures. Reprinted with permission from ref. [27] 


$$
\mathrm{I}_{\mathrm{x}} \%=\mathrm{I}_{\mathrm{x}} / \mathrm{I}_{\mathrm{C} 9} \times 100 \%
$$

Where $I_{X}$ is the integral value of the $\alpha$-position of $\beta$ $O-4(\mathrm{~A} \alpha), \beta-\beta(\mathrm{B} \alpha), \beta-5(\mathrm{C} \alpha)$, or $\beta-1(\mathrm{D} \alpha)$, the integration should be in the same contour level.

\subsection{Lignin utilization}

For the biorefining, the greatest challenges is to regulate the structure of lignin in order to both weaken the biomass recalcitrance and improve the lignin valorization. Although most of lignin is burned as low value fuels, the applications of lignin in various areas with or without modification has been extensively investigated, which can be divide into two major categories: (i) fuels and aromatic chemicals; (ii) materials [7882]. The main utilizations of industrial lignin in high value-added productions will be discussed in the following subsections.

\subsubsection{Fuels and aromatic chemicals}

Lignin and its derivatives have been developed into fuel sources in various forms, e.g. liquid, gas (syngas), solid (char), and liquid (aromatic) [82]. Generally, multiple strategies are used to depolymerize and degrade lignin, including thermochemical, catalytic hydrogenation, and gasification processes. The primary thermochemical processes, including fast and slow pyrolysis, are effective means for transforming the extracted industrial lignins into chars or oils by destroying the C-C and $\mathrm{C}-\mathrm{O}$ linkages in lignin. The oils obtained from the thermochemical process are mixed with many nonaromatic and aromatic compositions. However, each composition including high-molecular weight oligomers and light hydrocarbons has less than $1 \%$ content $[83,84]$. In addition, the generated condensation of lignin during the thermochemical process restricts the depolymerization of lignin. In general, the degree of condensation in lignin is different among lignin units in which the S-type lignins certainly favor thermal or chemical depolymerization, which due to the spaceoccupying of methoxy groups at 3 and 5 positions of the aromatic ring. Furthermore, the final pyrolysis temperature is another important factor that can affect the product distribution [85]. In the catalytic hydrogenation process, the liquid fuels can be produced by mixing the hydrogen gas and/or hydrogen-donating solvents with lignin at the temperatures between 300 and $600{ }^{\circ} \mathrm{C}$. However, this hydrogenation process often results in the deactivation of catalysts and the instability of hydrothermal process. Therefore, how to design suitable catalysts to figure out these defects, including design alternative supports and bimetallic functionalities, is a great challenge in the further studies. The gasification is performed by mixing the lignin with gas molecules, e.g. $\mathrm{CH}_{4}, \mathrm{CO}, \mathrm{CO}_{2}$ and $\mathrm{H}_{2}$, at various gasification temperatures and under different pressurees. During the gasification process, lignin is converted into gases and then is applied in syngas. For the petrochemical industry, the syngas has been identified as a promising material to be combusted for generating electricity and heat. In addition, the obtained syngas can be further converted into pure hydrogen through water gas shift reaction and gas separation, successively, which can be regard as a clean energy supporter for fuel upgrading in biorefineries and petroleum.

Lignin also can be utilized as a promising material for production of aromatic monomers, mainly including the methoxy phenolic monomers with a propanol- or alkyl-substituent at para position and demethoxylated phenolic species through different depolymerization strategies (i.e., acid/base, thermal depolymerization, reductive, and oxidative) [85-87]. Although, a mass of methods has been reported in recent years, only three primary products from lignin realized the industrial scale-up production: dimethyl sulfoxide, dimethyl sulfide, and vanillin. Therefore, how to prepare more products with high yields from isolated lignin through more green and economic methods is still a serious challenge.

\subsubsection{Lignin based materials}

Although some chemical additives and chemicals have been produced from industrial lignin, the amount of lignin from bioethanol refining and pulping up to $50 \mathrm{mil}$ lion tons every year, which incentives the lignin valorization research and development. As mentioned above, abundant hydroxyl groups (phenolic and aliphatic hydroxyl groups) and specific aromatic rings existed in lignin, which makes lignin to be a promising building block unit for various polymeric materials (e.g. polyesters, epoxide resins, and phenolic resins) [88-90] and lignin-based carbon materials (e.g. activated carbon, carbon fibers) $[78,91]$.

Several attempts have been made to partially replace phenol by lignin phenol-formaldehyde resins or ligninbased adhesives that were widely applied in various area, especially in plywood adhesives [92, 93]. In case of the lignin-modified resins, the highest bonding strengths reached up to $1.76 \mathrm{MPa}$ as $10 \%$ lignin was added into the resins in dry condition. In addition, Qiao et al. [92] produced the lignin-based PF resins with 10-60 wt\% of lignin, and found the adhesive strength reached to the optimal of $1.05 \mathrm{MPa}$ when $50 \%$ of lignin was added into the resin. However, due to the lower reactivity of industrial lignin, lignin only acted as filler rather than a phenol substitute in these studies, which resulted in an unsatisfactory result and higher energy requirement. Therefore, some research focus on 
using modified lignin as the phenol substitution. Sun et al. [94-96] found that the lignin with phenol modification in alkaline condition could significantly increase the reactivity and adhesive behavior of lignin. The lignin-based PF resins were successfully synthesized as plywood adhesives from the phenolic industrial lignin and the results showed that $50 \%$ phenol could be replaced and the bonding strength of the prepared layer plywoods could achieve the requirement of first grade plywood [94].

The functional lignin nano- and microparticles can be produced from lignin. The highest yield of lignin nanoparticles can reach up to $82.3 \%$ through a microwave acetylation process. The lignin-based nanomaterials can be used as potential adsorbent for the UV light adsorption [97]. The lignin nano- and microparticles were prepared by a facile method in the study of Ago et al. [98], and the preparation of lignin particles is expected to open up a new way for future material development. Lignin particles $(\sim 30 \mathrm{~nm}$ to $2 \mu \mathrm{m})$ could also be synthesized and utilized in the production of pickering emulsions [99]. In addition, kraft and alkali lignins were used as template for nanostructure materials to prepare hollow metal-phenolic capsules [100]. The lignin particle could be used as template in the synthesis of polymeric nanocoating from renewable tannins with metal ions. The nanocoating assembly and template disassembly approach were considered as green processes. The obtained hollow capsules were successfully in degrading the organic dye and regarded as environmentally friendly nanomaterials for contaminant removal.

In recent years, lignin has gained much attention as a potential source/precursor to prepare high value-added carbon materials due to its high carbon content. Activated carbon is a carbonaceous material with large surface area ranging from 500 to $2000 \mathrm{~m}^{2} / \mathrm{g}$ and various sizes of pores, and it has extremely high adsorbing capacity, such as for heavy metals. The preparation of activated carbon is mainly through carbonization, including physical and chemical activation techniques [101-104]. Physical activation is a technology that the lignin is subjected to carbonization at high temperatures (600$900^{\circ} \mathrm{C}$ ) with shielding gas (nitrogen and atmosphere) or oxidizing gas $\left(\mathrm{CO}_{2}\right.$ and steam), which is generally performed in a two-step process: carbonization and activation. However, for the chemical activation, some activating chemicals, such as $\mathrm{H}_{3} \mathrm{PO}_{4}, \mathrm{KOH}, \mathrm{K}_{2} \mathrm{CO}_{3}$, $\mathrm{NaOH}, \mathrm{K}_{2} \mathrm{CO}_{3}$ or $\mathrm{ZnCl}_{2}$, should be impregnated into lignin at temperatures in the range $450-900^{\circ} \mathrm{C}$ with shielding gas. During the chemical activation process, carbonization and activation proceed simultaneously and produce the materials with higher surface area and abundant micropore, which are important for the adsorption and other applications.

\section{Functional groups present in lignin and lignin modification}

\subsection{Functional groups present in lignin}

It is generally known that lignin contains several functional groups including carbonyl, methoxyl, aliphatic and phenolic hydroxyl, and carboxylic groups, etc. The structure of lignin has been thoroughly studied through various spectroscopic and chemical methods by our and other research groups, as the above mentioned. As shown in Table 2, the different functional groups of milled wood lignin from spruce pine lignin in kraft process are provided. It was found that hydroxyl $-\mathrm{OH}$ and alkyl $-\mathrm{OH}$ are the first two major functional groups in lignin. Importantly, these groups can offer the chemical sites which exhibit different possibilities for the chemical reactions. Therefore, lignin can be used as new chemical feedstock, particularly in the production of useful platform chemicals and bio-based polymers [79, 105-107].

\subsection{Lignin modification}

Abundant research has focused on lignin treat as heavy metal adsorbent, since it is abundance in nature, environmental friendly, thermal stability, and easy to access [108-111]. However, the research progress of ligninbased adsorbents is slow and the adsorption capacity is very low, for example, the heavy metals removal by lignin grafted polyacrylic acid is only $70.1 \mathrm{mg} / \mathrm{g}, 7.7 \mathrm{mg} / \mathrm{g}$, and $5.3 \mathrm{mg} / \mathrm{g}$ for $\mathrm{Cd}^{2+}, \mathrm{Co}^{2+}$, and $\mathrm{Hg}^{2+}$, respectively

Table 2 Functional groups found in 100, Cg repeat units of lignin [5]

\begin{tabular}{|c|c|c|}
\hline Functional groups & Spruce (MWL) & Pine lignin $(\mathrm{KL})$ \\
\hline \multicolumn{3}{|l|}{ Hydroxyl, $-\mathrm{OH}$} \\
\hline Total: & 120 & 120 \\
\hline 4-phenolic & 30 & 60 \\
\hline 1,2-benzenediol & - & 12 \\
\hline alkyl $-\mathrm{OH}^{\mathrm{a}}$ & 90 & 48 \\
\hline Carboxylic acid, $-\mathrm{COOH}$ & 5 & 16 \\
\hline \multicolumn{3}{|l|}{ Aldehyde, $-\mathrm{C}=\mathrm{O}$} \\
\hline Total: & 20 & 15 \\
\hline a-propyl & 7 & 5 \\
\hline$\beta$-propyl & 10 & 10 \\
\hline ү-propyl & 3 & - \\
\hline \multicolumn{3}{|l|}{ Phenylmethanol and ether } \\
\hline Noncyclic & 42 & $<6$ \\
\hline \multicolumn{3}{|l|}{ Cyclic } \\
\hline oxacyclopentene & 11 & 3 \\
\hline$\beta-\beta$, bi (cyclic ether) & 10 & 5 \\
\hline \multicolumn{3}{|c|}{ Ethene double bond, ${ }^{\prime} \mathrm{C}=\mathrm{C}^{<}$} \\
\hline a-phenyl- $\beta, \gamma$-ethene & 7 & - \\
\hline
\end{tabular}


[112, 113]. Therefore, physical, chemical, and enzymatic modifying methods are used to modify lignin structure to improve the efficiency of lignin application. In these methods, chemical modification is always adopted to enhance the lignin solubility, increase the blend compatibility, and improve the lignin mechanical properties [113-121]. It is well known that the lignin structure is rich with alcohol and phenol groups, therefore, the modification of lignin focus on esterification and etherification reactions $[122,123]$. The chemical modification of lignin gives several opportunities for its applications. The major modification approach including 1) depolymerization or fragmentation the lignin fraction into small fragments or aromatic macromers; 2) producing new chemical active sites by other solvents; and 3) chemical modification of the phenolic and alcohol hydroxyl groups.

\subsubsection{Alkylation}

Although lignin has a variety of functional groups, such as hydroxyl, carboxyl, carbonyl, and methoxyl groups, it has not reached a wide range of the utilization because of the complex structure. In order to overcome the problem, lignin is modified to create new chemical active sites to expand its applications. The alkylation usually refers to reaction with alcohols in the presence of a catalyst, such as hydrochloric acid. Lai et al. [124] studied the interactions between lignin and cellulase to better understand the biomass pretreatment and enzymatic hydrolysis. The ethanol organosolv lignin was alkylated with ethanol, resulting in the etherification of $C_{\alpha}$ of the lignin fraction. It was found that lignin alkylation could reduce the affinity of enzyme onto lignin, and the enzymatic hydrolysis efficiency can be enhanced. The other methods of alkylation include reactions with diazoalkanes under the anhydrous conditions to form ethers and the use of dialkylsulfate $\left(\mathrm{R}_{2} \mathrm{SO}_{4}\right)$ and base to produce alkylated lignin [125]. Results showed that these products are hydrophobic because of the ethers and esters production.

\subsubsection{Carboxylation}

Lignin can be modified with oxidoreductase enzymes laccase and peroxidase [125]. The phenoxy radicals generated in situ are unstable, and the polymerization and depolymerization reactions of lignin can be found in the processes $[126,127]$. It was found that the major substructures $\beta-O-4^{\prime}$ and $\beta-\beta^{\prime}$ of lignin can be broken up in the laccase-violuric acid solution. As a result, the content of methoxyl in lignin reduced, while the phenolic hydroxyl and carboxyl group contents increased [128]. The carboxyl group exhibited a good adsorption capability for heavy metal ions $[129,130]$. Therefore, the adsorption capacity could be increased to a large extent by grafting the carboxylic groups. Carboxymethylation was an effective method to improve the carboxylic groups of lignin. It was found that the carboxyl content could be increased to $3.61 \mathrm{mmol} / \mathrm{g}$ and the adsorption capacity of $\mathrm{Pb}^{2+}$ reach to $302.3 \mathrm{mg} / \mathrm{g}$ by using the microwaveassisted carboxymethyl lignin [131]. In a biorefinery process, the carboxymethyl lignin was grafted with $\mathrm{Al}^{3+}$ and $\mathrm{Mn}^{2+}$, which was utilized for the textile dye and Procion blue MX-R (PB) adsorption [132]. The results showed that the adsorption capacities were 73.52 and $55.16 \mathrm{mg} / \mathrm{g}$, respectively. In addition, about $95.83 \%$ of dye-contaminated industrial effluents was removed by using the modified lignin material. Shweta and Jha [133] reported that the biodegradable carboxymethylated lignin-tetra ethoxysilane nanocomposites (CML-T) were prepared by surface modification. The composite exhibited 70.72 and $81.79 \%$ re moval of $\mathrm{Ni}^{2+}$ and $\mathrm{Cd}^{2+}$, respectively. The composite is proposed to be used in the wastewater treatment and biofilter packaging material for environmental protection.

\subsubsection{Sulfonation and other modifications}

The methylene sulfonate and sulfonate can be added to the lignin molecule. The sulfonate lignin is highly soluble in water and commonly used as dispersants in cement admixtures, lubricating agent, and additive in viscosity reducer [121]. It was found that the molecular weight and degree of lignosulfonates were crucial in determining their efficiency in industries. The amination of lignin is used to produce lignin based polymers and materials. The amination of lignin with epoxy amines was proved to enhance the heavy metal adsorption capacity. The amino lignin can be used in the field of environment protection [134]. Phenolation can improve the reactivity of lignin by increase the content of phenolic hydroxyl groups. The modification is considered to be a promising substitute for phenol-formaldehyde synthesis. The major oxidation reactions of lignin are alkylation, sulfomethylation, sulfonation, nitroxide, and oxyalkylation. In addition, oxidation, deduction, and hydrolysis can also improve the reactivity of lignin and produce phenolic compounds from lignin [121].

\section{An overview of the leather industry}

Leather manufacturing is an ancient technology in the world. The raw hides and skins are usually used for the leather production, which provides versatile properties of materials for various consumer productions such as bags, shoes and garments, etc. The leather production process includes three main steps, namely pre-tanning preparation (beam house process), tanning process, and finishing process. The beam house stage is applied to prepare the hide or skin for subsequent tanning process. In this stage, some conventional methods such 
as soaking, liming, unhairing, splitting, and bating etc. are carried out, which discharge about $70 \%$ of the total pollution arising in leather processing [135]. Because the chemical sodium sulfide and lime are used in this process, high amount of suspend substance (SS) including lime sullage and sulfide in wastewater is produced. Additionally, $60-70 \%$ of chemical oxygen demand $(\mathrm{COD})$ and biochemical oxygen demand $\left(\mathrm{BOD}_{5}\right)$ pollution load are generally present in this process [135]. Tanning process is very important during leather production, which could improve thermal stability and strength of the leather. In general, there are two main types of tanning including chrome and vegetable tanning. The vegetable tanning process always consume a long time for the hide or skin to adsorb the dyes, which use tanning agents from nature. In recently years, vegetable tanning agents such as syntans [136], oil tanning agent [137], and unnatural d-amino acid (D-AA) [138] as substitutes for chrome-free tanning have been mainly researched. The chrome-free tanning materials are considered as a suitable eco-friendly alternative because of minimize chrome tanning impact to the environment. However, the vegetable tanning result in excessive loading in the leathers, which reduces its versatility of the products and decrease the leather resource utilization. Chrome tanning, more than $90 \%$ of the global leather production process, is more superior to vegetable tanning method $[139,140]$. In the chrome tanning process, basic chromium salt are popularly used to interact with the collagen molecules of the hide/skin to give leather its characteristic properties. However, in the conventional chrome tanning process, only $65-75 \%$ of the chrome is up-taken and effectively utilized [141, 142]. It was found that $2 \%$ of chromium is simply adsorbed and $40 \%$ chromium appears to be bound to the collagen [143]. As a result, the high concentration of chromium remains in the tanning liquor. However, in the leather manufacturing process, the chrome containing effluents were firstly treated and most of the chrome is recovered. The small amount of chrome existed in the solution was discharged into comprehensive wastewater, and finally get into sludge. The final stage of leather processing consists of surface coating, for example, oiling, brushing, padding, polishing, ironing, glazing and tumbling processes [144]. In this stage, dyes are added to the wet process to impact the sensory characteristics of the final products. For example, the interior coloration, uniformity, and chemical and physical stability of the leather are determined in the finishing process, which is important in tanning operations. Because the wet finishing course of this process is performed in liquid medium, a significant volume of wastewater is produced, which contains a high concentration of dyes.

\section{1 $\mathrm{Cr}$ removal from wastewater}

In the conventional process of leather tanning industry, the raw skin was treated by chrome, inorganic and organic chemical, and surfactants [145]. Therefore, high concentration of chemical oxygen demand (COD, 1-4 g/l), biogical oxygen demand (BOD, $0.3-0.8 \mathrm{~g} / \mathrm{l}$ ), total organic carbon (TOC, $0.35-1.7 \mathrm{~g} / \mathrm{l}), \mathrm{Cr}(\mathrm{VI})(5-20 \mathrm{mg} / \mathrm{l})$ and $\mathrm{Cr}$ (III) $(5-300 \mathrm{mg} / \mathrm{l})$, and phenolic compounds (100-500 $\mathrm{mg} / \mathrm{l})$ are generally present in the tannery wastewater [146-149]. In addition, the effluent generated from the dyeing process is characterized by dark brown color and strong odor. Therefore, in the tanning process, a mass of pollutants and water are discharged [149]. In some area, some sediments with highly polluted those resulted from discharge of chemicals has already affected the ecological function of rivers, [150]. The lands and rivers have been contaminated by wastewater, and people are affected by the low quality of social environment and drinking water $[151,152]$. Therefore, the relatively high concentration of contaminants with poor biodegradability in tannery wastewater was released to the environment and poses the challenge to the environment.

Among the many chemicals used in the tanning process, trivalent chromium $\mathrm{Cr}$ (III) is used in the tanning industry, and the hexavalent chromium $\mathrm{Cr}$ (VI) will be formed during the oxidization process by the uncontrollable natural bio-transformations in the environment. $\mathrm{Cr}(\mathrm{VI})$ is the most toxicity heavy metal in the tannery wastewater. Although the effluents produced are normally treated with physical or chemical methods in the industry, the tannery wastewater are always high toxicity and more complicated, and approximately $3 \%(\mathrm{w} / \mathrm{w})$ of $\mathrm{Cr}$ (III) is still exist in the solid residue [153]. As reported by Saranraj and Sujitha [154], the leather production in the world annually produced about 40 million $\mathrm{L}$ of $\mathrm{Cr}$ polluted wastewater every year. However, the concentration of $\mathrm{Cr}$ in the spent float increased because of its low recovery and low-rate utilization [155]. Therefore, the effluents containing $\mathrm{Cr}$, dyes, and other chemicals, are discharged into the environment especially into the water bodies and cause serious environmental pollution.

In the nature environment, $\mathrm{Cr}$ exists in two oxidation forms in aqueous solution including $\mathrm{Cr}$ (III) and $\mathrm{Cr}(\mathrm{VI})$. Cr (III) showed low solubility, immobile properties, and less toxic. Cr (III) is considered an important trace element which is good for our body [156, 157]. However, it was found that $\mathrm{Cr}$ (III) can be oxidized to $\mathrm{Cr}$ (VI) in the forms of chromate $\left(\mathrm{CrO}_{4}{ }^{2-}\right)$ and dichromate $\left(\mathrm{Cr}_{2} \mathrm{O}_{7}{ }^{2-}\right)$, which are longstanding, highly mobile, and most toxic to human beings [158-161]. The $\mathrm{Cr}$ concentration ranges from 5.2 to $208,000 \mathrm{mg} / \mathrm{l}$ in nature water [162]. However, in drinking water, the maximum permissible limit is 0.01 and $0.10 \mathrm{mg} / \mathrm{l}$ for for $\mathrm{Cr}(\mathrm{VI})$ and total $\mathrm{Cr}$, respectively. [158]. The excess of $\mathrm{Cr}$ (III) in water can cause allergic 
skin reactions and cancer [162], and $\mathrm{Cr}$ (VI) is about 300 times more toxic than Cr (III) [163], which is carcinogenic and mutagenic to organisms [164]. Therefore, the leather tanning wastewater that directly pours into the water bodies without any treatment can cause environmental problems. In addition, synthetic dyes which contain water-soluble reactive and acid dyes with azobased chromophores and chemicals are used in the tanning operations in the leather production. These compounds are common pollutants to the environment, which can cause environmental problem as well [165]. It is necessary to remove $\mathrm{Cr}$ and dyes from the wastewater and prevent further contamination $[166,167]$.

\subsection{Present disposal methods for the $\mathrm{Cr}(\mathrm{III}) / \mathrm{Cr}$ (VI) removal from wastewater}

At present, a wide range of physic-chemical and biological methods have been used in wastewater treatment processes. In general, the classical available methods of the $\mathrm{Cr}$ removal from the wastewater include chemical precipitation [168], ion exchange [169], reduction [170], electrochemical [171], reverse osmosis [172], and adsorption $[173,174]$. However, these traditional methods have significant disadvantages and are not completely suitable for the removal of $\mathrm{Cr}$ ions form tannery wastewater, which are high cost and energy consumption, limited applicability, low efficiency, and large amounts of sludge produced.

\subsubsection{Chemical precipitation}

Chemical precipitation is carried out by addition of chemicals, such as lime $\left(\mathrm{Ca}\left(\mathrm{OH}_{2}\right)\right)$ and caustic soda $(\mathrm{NaOH})$, to form an insoluble hydroxide precipitation such as $\mathrm{Cr}(\mathrm{OH})_{3}$. It was found that lime precipitation is one of the most effective methods to remove $\mathrm{Cr}$ from wastewater [175]. However, the traditional precipitation methods have limitations. For examples, the obtained effluents still do not meet the required discharge targets. As we know, hexavalent chromium usually exists as chromate $\left(\mathrm{CrO}_{4}{ }^{2-}\right)$ and dichromate $\left(\mathrm{Cr}_{2} \mathrm{O}_{7}{ }^{2-}\right)$ forms, these two ions are difficult to precipitate. Therefore, chemical precipitation of $\mathrm{Cr}(\mathrm{VI})$ from industrial wastewater is always followed by transfer $\mathrm{Cr}(\mathrm{VI})$ to $\mathrm{Cr}$ (III), and then alkali was used to precipitate the $\mathrm{Cr}$ (III) cations. Gheju and Balcu [176] found that the maximum removal efficiency for the $\mathrm{Cr}$ (III) and $\mathrm{Cr}$ (VI) under alkaline conditions can reach to $98.5 \%$. However, the precipitation process is affected by the factors of $\mathrm{pH}$, organic matter, and other ions of the effluent [177]. Furthermore, the precipitation is inefficient when the chromium concentration is low. Therefore, some residual inorganic species such as chloride and chromium are still present in the tannery wastewater. In addition, the disposal of produced chromium hydroxide and sludge are difficult and expensive as well.

\subsubsection{Ion exchange}

Several studies have been carried out to use commercially ion-exchange resins to remove $\mathrm{Cr}$ from water [169, 178180]. The ion-exchange process has been proved to be an effective method to remove $\mathrm{Cr}$ (VI) from the tannery wastewater. The metal can be recovered and the process is low-energy demands. Edebali and Pehlivan [179] reported that more than $93 \%$ of $\mathrm{Cr}(\mathrm{VI})$ can be removed at $\mathrm{pH} 3.0$ as the optimal condition from the wastewater by resin. A novel anion exchange resin poly-epichlorohydrindimethylamine (EPIDMA)/D310 was used to remove $\mathrm{Cr}$ (VI). The results showed excellence performance of removing Cr (VI) by the basic anion exchange resin D310 supported cationic EPIDMA polymer [180]. Rengaraj et al. $[169,181]$ used IRN77 and SKN1cation exchange resins to remove $\mathrm{Cr}$ from aqueous solutions. The result showed that over $95 \%$ of $\mathrm{Cr}$ ions were removed under the optimal condition. Meanwhile, it presented good reversible uptake of $\mathrm{Cr}$ from aqueous solutions. However, the resins are always expensive, and the chemical and thermal properties of the resin may influence the removal efficiency of the heavy metals. In addition, the ions such as sulfate and chloride exist in the aqueous solution showed reduced role for $\mathrm{Cr}$ removal by resin at specific conditions [178].

\subsubsection{Electrochemical and electrocoagulation}

Electrochemical treatment was carried out for the removal of sodium chloride and organics of soak liquor from various process effluents $[182,183]$. The electrochemical oxidation process by the graphite/graphite system was found to be effective for the removal of COD and organic pollutants in the wastewater. Many researchers have applied electrolytic reduction to treat tannery wastewater. The electrochemical reactor with different electrodes materials should be firstly equipped. Szpyrkowicz et al. [184] utilize undivided electrochemical reactor with $\mathrm{Ti} / \mathrm{Pt}-\mathrm{Ir}, \mathrm{Ti} / \mathrm{PbO}_{2}, \mathrm{Ti} / \mathrm{PdO}-\mathrm{Co}_{3} \mathrm{O}_{4}$, and $\mathrm{Ti} / \mathrm{RhO}_{\mathrm{x}}-\mathrm{TiO}_{2}$ anode and stainless steel cathode to treat the tannery wastewater. Results showed that the removal efficiency of the pollutants was significantly influenced by the type of the anode material and electrochemical parameters. In the electrocoagulation method, soluble electrode such as mild steel electrodes was found to be more effective for the removal of pollutants than the aluminum electrode [185]. According to Golder et al. [183], electrocoagulation method with mild steel as electrode material was used for treating basic chrome sulfate in the tanning process. Combined effect of chemical precipitation, co-precipitation, sweep coagulation and adsorption of $\mathrm{Cr}$ during electrocoagulation process is observed. However, there are some disadvantages during 
the electrochemical treatment of wastewater. For example, the Cr recovery with Fe electrode showed a dark coloration because of the iron [186]. Furthermore, the electrical energy was consumed by the electro- methods in the tannery wastewater treatment.

\subsubsection{Emerging treatment technologies}

Except for the common methods above, the advanced technologies has been applied to remove $\mathrm{Cr}$ from the tannery wastewater. For example, the membrane process can treat the tannery leather effluents to remove the salt content and recovery the $\mathrm{Cr}$ from the residual effluents [187]. Reverse osmosis (RO) with a special membrane was used to remove the inorganic pollutants from the wastewater [188]. RO membrane was used to remove $\mathrm{Cr}$ from electroplating effluents, resulting in as high as $99 \%$ of $\mathrm{Cr}$ removal efficiency at the optimized conditions [189]. The results showed that the RO treatment is proved to be the most effective method to remove refractory organic pollutants and metal contaminated effluents of electroplating and similar industries, resulting high quality of water which similar to the potable water. Different ultrafiltration (UF) and nanofiltration (NF) membranes were applied in the leather tanning industry for the removal of $\mathrm{Cr}$ from the wastewater [190]. In addition, research articles have focued on the treatment of textile wastewater by using biodegradation/biodecolourization by fungi [191]. The fungi treatments of leather dyes and tannery wastewater are rarely reported because the fungal strains in the treatment of wastewater are difficult to be selected. Furthermore, advanced oxidation processes (APOs) are applied for the treatment of tannery wastewater, like Fenton, ozonation, and photo Fenton process, Ozone/UV radiation are potential alternatives for the tannery effluent treatment [192, 193]. Among these APOs, ozonation is an effective method to remove color from the wastewater.

In summary, the above methods for the wastewater treatments have advantages and disadvantages. Moreover, high capital cost has limited their widely commercial utilization. For example, photoelectron chemistry was used to reduce the $\mathrm{Cr}$ (VI) and leather wastewater simultaneously on nanoporous $\mathrm{Ti} / \mathrm{TiO}_{2}$ electrodes [194]. Results showed that about $98-100 \%$ of $\mathrm{Cr}$ (VI) was reduced, but the preparation of $\mathrm{Ti} / \mathrm{TiO}_{2}$ thin-film electrodes is complex and expensive. Among these methods, adsorption has been proved to be a promising approach in Cr removal [195]. Activated carbon has been used to adsorb chromium from water/wastewater. Mohan et al. [196] developed an efficient adsorption process for the removal of $\mathrm{Cr}$ (III) from tannery effluents by an activated carbon prepared from coconut shell fibers. Results showed that the adsorption capacity of $\mathrm{Cr}$ (III) by the activated carbon is comparable to many other sorbents that used to treat the water/wastewater. However, the production of active carbon is also expensive. Therefore, it is worthwhile to explore novel and low-cost adsorbents for the removal of $\mathrm{Cr}$ from wastewater. Nowadays, biosorbents derived from low-cost natural sources such as lignocellulosic biomass have been investigated by the researchers for the removal of chromium in preference to the other conventional absorbent materials.

\subsection{Lignocellulosic biomass and other non-living materials as biosorbents for the removal of $\mathrm{Cr}$}

Biosorbent has attracted much attention in the application of heavy metal removal from water and wastewater in recent years. The biosorption is considered to be a facile, low-cost, and easy-design alternative method to remove the heavy metals. Another advantage is that the cheap biosorbent can be regenerated by suitable desorption process by chemical reagent such as acid and base solvents. The adsorptions of Cr (VI) onto different biosorbents are summarized and shown in Table 3. As shown in Table 3, the biosorbents are always produced by living or dead lignocellulosic biomass and a vast array of substances, e.g. metals, radionuclides, and organics. Non-living materials are widely used in removing heavy metals including potato peels, sawdust, cellulose, chitosan, and lignocellulosic materials, etc. [197-223]. In addition, algal, bacteria, fungi, and yeast have also attracted much attention as new adsorbents to adsorb heavy metal ions. However, the cheap naturally and abundant biosorbents should be functionalized with various inorganic and organic chemicals firstly to get a high biosorption capacity. For example, cotton fiber was modified with $\mathcal{\varepsilon}$-caprolactone and oxydianiline in the presence of $\mathrm{V}_{2} \mathrm{O}_{5}$ catalyst. The results showed that the cotton fiber exhibited the maximum adsorption capacity $(696.47 \mathrm{mg} / \mathrm{g})$ of rhodamine 6G (R6G) dye through chemical interaction forces [224]. Cellulose-based biosorbents were designed and produced by grafting acrylic acid and acrylamide, and the highest adsorptions capacities of $\mathrm{Cr}$ (III), $\mathrm{Cu}$ (II), and Co (II) were $220.64,213.49$, and $137.55 \mathrm{mg} / \mathrm{g}$ at a wide $\mathrm{pH}$ range of 3.0-5.0, respectively [225]. The reason for $\mathrm{Cr}$ (III) adsorption was the stronger attraction to the long pair of electrons both in oxygen and nitrogen atom to form more stable complexes, however, the $\mathrm{Cu}$ (II) and Co (II) adsorption were ascribe to the carboxyl/carbonyl groups. Surface functional groups were found to be the important factor in metal ions adsorption [137]. In addition, hydroxyethylcellulosebased supersorbent and carboxymethyl celluloseethylenediamine polymer were used for $\mathrm{Cr}$ (VI) adsorption. It was found that the maximum sorption capacities of $\mathrm{Cr}(\mathrm{VI})$ calculated by Lamgmuir isotherm model 
Table $3 \mathrm{Cr}$ adsorption by various biosorbents from lignocellulosic biomass and other materials

\begin{tabular}{|c|c|c|c|c|}
\hline Adsorbent & $\mathrm{Q}_{\max }(\mathrm{mg} / \mathrm{g})$ & $\mathrm{pH}$ & Mechanism proposed & Reference \\
\hline Chitosan & 273.0 & 3.0 & Electrostatic attraction & [197] \\
\hline Non-crosslinked chitosan & 80.0 & 5.0 & Electrostatic attraction & [198] \\
\hline Sugarcane & 23.0 & 1.9 & - & [199] \\
\hline Rice & 285.7 & 2.0 & Electrostatic attraction & [200] \\
\hline Rice husk & 52.1 & 2.0 & Reduction reaction & [201] \\
\hline Activated biochar-Pomelo peel & 57.6 & - & $\begin{array}{l}\text { Electrostatic interaction } \\
\text { and ion exchange }\end{array}$ & [202] \\
\hline Cellulose-based adsorbent & 209.6 & 2.0 & Reduction reaction & [203] \\
\hline Ionic liquid functionalized cellulose & 181.2 & 2.0 & Anion exchange-reduction mechanism & [204] \\
\hline Nanocarbon bridged nanomagnetite network & - & 3.0 & Electrostatic attraction & [205] \\
\hline $\begin{array}{l}\text { Mesoporous carbon sponge from } \\
\text { microcrystalline cellulose }\end{array}$ & 93.9 & $2.0-5.5$ & Electrostatic attraction & [206] \\
\hline Brown coals & $\begin{array}{l}81 \% \text { out of } 100 \mathrm{ppm} \\
\mathrm{Cr}(\mathrm{VI})\end{array}$ & $2.0-3.0$ & Reduction reaction & [207] \\
\hline Humic acids extracted from brown coals & 0.64 & 3.2 & Electrostatic attraction & [208] \\
\hline Coconut coir & 6.3 & 2.0 & Reduction reaction & [209] \\
\hline Coconut coir & $\sim 20$ & 3.0 & Reduction reaction & [210] \\
\hline Coir pith & 196 & 2.0 & Reduction reaction & [211] \\
\hline Modified sludge biomass & 255.3 & & Electrostatic attraction, lon exchange & [212] \\
\hline Biochar-supported CMC-stabilized FeS nanoparticles & 130.5 & 5.5 & $\begin{array}{l}\text { Reduction reaction and } \\
\text { surface sorption }\end{array}$ & [213] \\
\hline Tannin-immobilzed nanocellulose & 103.3 & 2.0 & Reduction reaction & [214] \\
\hline Persimmon tannin gel & 287.0 & 3.0 & Reduction reaction & [215] \\
\hline $\begin{array}{l}\text { Starch and sodium carboxymethyl cellulose-coated Fe } \\
\text { and Fe /Ni nanoparticles }\end{array}$ & $\begin{array}{l}95.7 \% \text { (maximum } \\
\text { removal efficiency) }\end{array}$ & 2.0 & Reduction reaction & [216] \\
\hline Hemicellulose-based hydrogels & 47.5 & 3.0 & - & {$[217]$} \\
\hline Sawdust Acacia arabica & 111.6 & 6.0 & lon exchange & [218] \\
\hline Modified pine & 30.49 & 2.0 & Electrostatic attraction & [219] \\
\hline Oka tree & 1.74 & 3.0 & Electrostatic attraction & [220] \\
\hline Rice straw & 3.15 & 2.0 & Reduction reaction & [221] \\
\hline Dead fungal biomass & 117.3 & 1.0 & - & [222] \\
\hline Bacteria & 39.9 & 2.7 & Reduction reaction & [223] \\
\hline
\end{tabular}

were $909 \mathrm{mg} / \mathrm{g}$ and $177.6 \mathrm{mg} / \mathrm{g}$, respectively [226, 227]. Magnetic cellulose/activated carbon showed efficient removal of organic dyes and Congo red from wastewater. The sorbent could be recovered completely and easily with magnetic processes. The preparation of the cellulose-based adsorbents was proved to be "green" and low cost, which might be a promising candidate of high efficiency for dye removal [228, 229]. In general, the functionalization of the above biosorbents always contains increasing the binding sites or binding some functional groups on its surface. Therefore, the treatment of wastewater containing heavy metals by suitable biosorbents showed cheap and high biosorption capacity [230, 231].

\section{$5 \mathrm{Cr}$ removal from wastewater by using lignin- based biosorbents}

Recently, lignin has been suggested as an environmentally friendly and cheap alternative for adsorbing pollutants such as heavy metals [110-112] and organic dyes $[132,232]$ or for activated carbon production [142, 233]. As we known, lignin is an amorphous phenolic network polymer and the content of the phenolic hydroxyl group is very low. It has been reported that the maximum adsorption capacities of $\mathrm{Cr}$ (III) and $\mathrm{Cr}$ (VI) were quiet low for kraft lignin. Only 17.97 and $5.64 \mathrm{mg} / \mathrm{g}$ according to the sorption equilibrium equation, respectively [223, 229]. Therefore, in order to increase the adsorption efficiency of lignin-based biosorbents, the production of 
large surface area, strong binding-site, and high and quick adsorption properties of lignin materials are necessary.

\subsection{Modification of lignin for $\mathrm{Cr}$ removal from wastewater} The modification of lignin has been widely studied to improve the adsorption capacity of metal ions. The ligninbased biosorbents has been prepared by incorporating functional groups such as oxygen, sulfur, and nitrogen [234]. da Silva et al. [232] reported that sugarcane bagasse lignin was carboxy-methylated to obtain dye adsorbent. The modified lignin was further complexed with $\mathrm{Fe}^{3+}$ ion and used to remove Brilliant Red 2BE dye from the aqueous solutions in the textile industry. The results showed that the obtained lignin material was a good alternative adsorbent to remove Brilliant Red 2BE textile dye from wastewater. The sorption mechanism was electrostatic attraction, the negatively charged dyes adsorb onto the positively surface charged lignin-based material [232]. Yao et al. [235] used sodium lignosulfonate as raw material to produce lignin hydrogel, and lignin was graft-copolymerized with acrylamide and maleic anhydride. It was found that the sulfur-containing groups, nitrogen atom, and oxygen atom in the carboxyl groups could be the adsorption sites for the heavy metals.

Another methods for prepare lignin-based adsorbents are chemical modification with different chemicals, such as acrylic acid [236], vinyl alcohol, polyaniline [237], and polyethylenimine [238]. Alkaline lignin was modified with acrylic acid by radical graft copolymerization, numerous carboxyl groups were introduced for binding the heavy metals. It was found that the novel lignin-based biosorbent exhibited a relatively high biosorption capacity. Kwak et al. reported that water-resistant lignin/poly (vinyl alcohol) (PVA) blend fibers by glutaraldehyde crosslink exhibited notable Cr (VI) adsorption capacity of $350.87 \mathrm{mg} / \mathrm{g}$. The glutaraldehyde-crosslinked lignin/PVA blend fiber was found to be a good choice for removing of heavy metal from textile wastewater. However, the $\mathrm{pH}$ of the wastewater strongly affects the adsorption capacity of $\mathrm{Cr}$ (VI), since the $\mathrm{pH}$ of the solution influence the speciation of $\mathrm{Cr}(\mathrm{VI})$ and the surface charge of the adsorbent. To reuse the adsorbent, the heavy metal can be released in alkaline solutions thus the lignin-based biosorbent was regenerated [232]. Although the removal of $\mathrm{Cr}$ (VI) by regenerated lignin-based biosorbent decreased as the readsorption cycle increased, the glutaraldehyde-crosslinked biosorbent still exhibited high adsorption capacity of $\mathrm{Cr}$ (VI). In addition, a few studies focused on the lignin-based resin production on $\mathrm{Cr}$ adsorption. Wu et al. [239] reported that $\mathrm{Cr}$ (III) can be successfully removed from real wastewater using lignin that isolated from black liquor. The maximum adsorption capacity was $17.97 \mathrm{mg} / \mathrm{g}$ according to Langmuir two-surface model. However, the lignin-based resin showed less adsorption capacities. In order to increase the adsorption capacity, a lignin-based resin was synthesized by sodium lignosulfonate and glucose under sulfuric acid condition for adsorption of $\mathrm{Cr}$ (VI) from wastewater solutions [240]. Results showed that the maximum $\mathrm{Cr}$ (VI) adsorption capacity was $74.29 \mathrm{mg} /$ $\mathrm{g}$, indicating that the lignin-based resin could also be an efficient biosorbent for the removal of $\mathrm{Cr}$ from wastewater. In the preparing process, 5-hydroxymethylfurfural and levulinic acid were produced from glucose, and the acetylation reaction of desulfonated lignosulfonates occurred. Therefore, the adsorption sites such as carboxyl, lactones, and phenolic groups are present on the globular ligninbased resin, which were effective to absorb the heavy metals. The adsorption capacity was increased by the lignin-based resin. Although significant adsorption capacities of heavy metals appear possible after lignin modification, the chemicals and functional groups introduced will lower the biodegradability of lignin. Therefore, the biodegradability of modified lignin is still the focus of concern, and more research should be investigated in the future.

Recently, graphene oxide (GO) is introduced into lignin as a three-dimensional structure adsorbent. As we known, GO is oxidized from graphene, which consisting abundant $O$-containing functional groups such as $-\mathrm{COOH},-\mathrm{OH}$, and epoxy groups on its surface. This helps to adsorption of heavy metals ions. In our research group, lignosulfonate (LS) was modified with GO by a one-step hydrothermal process in Teflon-lined autoclaves (Fig. 6) [241]. It was found that the prepared freestanding and flexible lignin-based hydrogel exhibited an ultrahigh adsorption capacity of $1308 \mathrm{mg} / \mathrm{g}$ for $\mathrm{Pb}$ (II) in a short time. In addition, the biosorbent is low cost, environmental friendly, and recyclable, which could be a promising adsorbent for the purification of tannery wastewater. A study conducted by Chauke et al. [242] revealed that $\mathrm{GO}$ based nanocomposites can remove highly toxic $\mathrm{Cr}$ (VI) from wastewater. The maximum adsorption capacity of $\mathrm{Cr}$ (VI) ranged from $606.1 \mathrm{mg} / \mathrm{g}$ to $666.7 \mathrm{mg} / \mathrm{g}$. Although little research has been done on the removal of $\mathrm{Cr}(\mathrm{VI})$ using lignin-based $\mathrm{GO}$ materials especially from tannery wastewater. It is believed that this promising material could be an attractive adsorbent for heavy metal ions from wastewater in the future.

\subsection{Lignin-based activated carbons production and $\mathrm{Cr}$ adsorption}

Previous works have revealed that lignin can be activated with $\mathrm{KOH}$ [243]. The papermaking black liquor lignin was activated with $\mathrm{KOH}$, resulting in a high surface area $\left(2943 \mathrm{~g} / \mathrm{m}^{3}\right)$. Lignin-based activated carbon showed high adsorption capacity of heavy metals. Fierro et al. [244] reported that $\mathrm{KOH}$ was more effective than $\mathrm{NaOH}$ in lignin activation. The surface area and micropore 


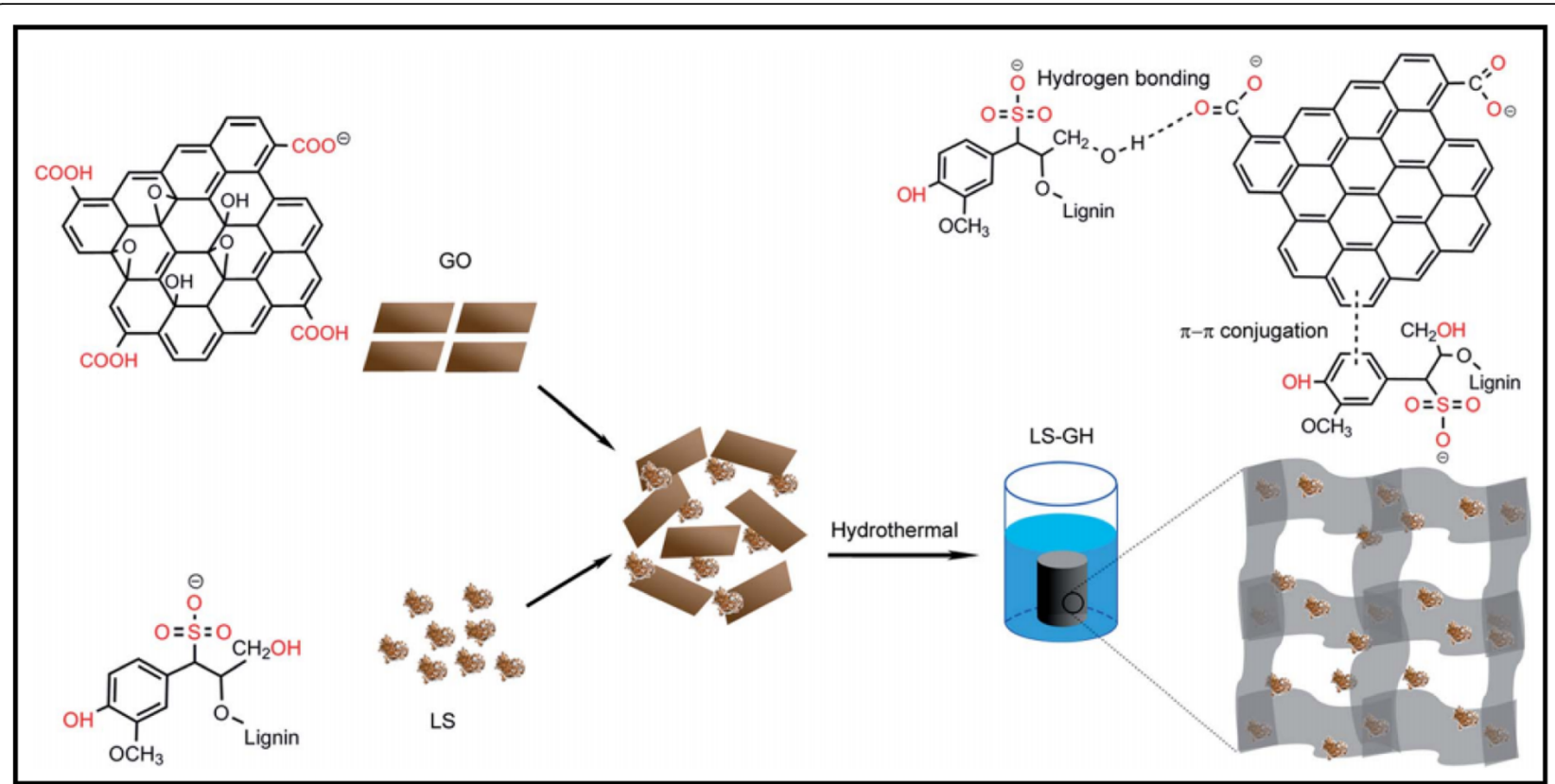

Fig. 6 The schematic of the one-step self-assembled of GO and LS for lignin-based biosorbent preparation. Reprinted with permission from ref. [241]

volume of $\mathrm{KOH}$-activated lignin was 1.5 and 1.2 times higher than those of $\mathrm{NaOH}$-activated lignin, respectively. The $\mathrm{KOH}$-activated lignin is microporous and showed high surface area up to $3100 \mathrm{~m}^{2} / \mathrm{g}$. The lignin/KOH ratio was the main factor influencing the surface area of the activated carbon. Furthermore, the main activation process was connected with the produced volatile matters, e.g. $\mathrm{H}_{2} \mathrm{O}, \mathrm{CO}_{2}$ and $\mathrm{CO}$. Moreover, the hydroxide vapor should not be neglected because $\mathrm{K}_{2} \mathrm{CO}_{3}$ produced was found to be effective in lignin activation. The following equation exhibited the chemical reaction of lignin and $\mathrm{MOH}$ as shown in Eq. (6), in which $\mathrm{M}$ is the $\mathrm{K}$ or $\mathrm{Na}$.

$$
6 \mathrm{MOH}+2 \mathrm{C} \leftrightarrow 2 \mathrm{M}+3 \mathrm{H}_{2}+2 \mathrm{M}_{2} \mathrm{CO}_{3}
$$

Another method for activated carbon production is based on orthophosphoric acid $\left(\mathrm{H}_{3} \mathrm{PO}_{4}\right)$ activation. The adsorption of $\mathrm{Cr}(\mathrm{VI})$ was conducted by the $\mathrm{H}_{3} \mathrm{PO}_{4}$-activated lignin (PAL) via microcolumn technique [161, 245]. The chemical modification may occur between the $-\mathrm{OH}$ and $-\mathrm{COOH}$ groups of lignin and $\mathrm{H}_{3} \mathrm{PO}_{4}$ molecular. Thus, the groups ${ }^{\mathrm{P}} \mathrm{P}(\mathrm{O}) \mathrm{OH}$ and $-\mathrm{P}(\mathrm{O})(\mathrm{OH})_{2}$ will be present on the activated lignin. Results showed that the sorption capacity of $\mathrm{Cr}$ (VI) was $77.85 \mathrm{mg} / \mathrm{g}$, which was higher than other materials. In addition, the adsorption of $\mathrm{Cr}$ (VI) was always influenced by salt in industrial wastewaters. Albadarin et al. [235] indicated that some salts such as $\mathrm{KNO}_{3}$ and $\mathrm{NH}_{4} \mathrm{NO}_{3}$ contained $\mathrm{NO}^{3-}$ in aqueous solution may facilitate the $\mathrm{Cr}(\mathrm{VI})$ adsorption because of the $\mathrm{Cr}$ (VI) reduction to $\mathrm{Cr}$ (III).
However, some anions such as $\mathrm{P}_{2} \mathrm{O}_{7}{ }^{2-}$ and $\mathrm{CO}_{3}{ }^{2-}$ in solution will hinder the uptake of $\mathrm{Cr}(\mathrm{VI})$, since these two anions are negatively ions and will serve as an electron acceptor to compete with hexavalent chromium $\left(\mathrm{Cr}_{2} \mathrm{O}_{7}{ }^{2}\right.$ ${ }^{-}, \mathrm{CrO}_{4}{ }^{2-}, \mathrm{H}_{2} \mathrm{CrO}_{4}$, and $\left.\mathrm{HCrO}^{4-}\right)$ on the surface of the activated lignin biosorbents.

\section{3 $\mathrm{Cr}$ adsorption mechanisms}

In aqueous solutions, the hexavalent chromium always exist in different anionic forms: $\mathrm{H}_{2} \mathrm{CrO}_{4}, \mathrm{Cr}_{2} \mathrm{O}_{7}{ }^{2-}, \mathrm{HCrO}^{4}$ ${ }^{-}$, and $\mathrm{CrO}_{4}{ }^{2-}$, and the major $\mathrm{Cr}$ containing ions depends on the solution $\mathrm{pH}$ [246]. Because the $\mathrm{pH}$ value could influence the anionic forms of $\mathrm{Cr}$ (III)/Cr (VI) and the lignin-based biosorbents surface charge. Most of the research showed that the $\mathrm{Cr}$ (III)/Cr (VI) removal was strongly $\mathrm{pH}$-dependent and increased with increasing $\mathrm{pH}$ [201-223]. However, more attention should be paid to the structure of lignin. As we know, the lignin molecule contains three precursors, guiacyl, syringyl, and $p$-hydroxyphenol, which has carboxylic and phenolic functional groups those can form strong electrostatic attraction with metal ions. At different pHs, these functional groups of lignin exhibited different binding constants with various species of chromium $(\mathrm{Cr})$. For example, at low $\mathrm{pH}$, the surface of lignin carries less negative charges and can readily absorb the anion of $\mathrm{Cr}$. When increasing the $\mathrm{pH}$ value, decreased adsorption efficiency is expected. This is because the adsorption sites and surface acidity of lignin were affected by the high concentration of $\mathrm{OH}^{-}$ion that may compete with lignin for the chromate ions. Therefore, 
the metal ion adsorption was mainly related to the carboxylic- and phenolic-type surface groups of lignin. Guo et al. [247] has investigated the surface site of lignin sorption at different pHs. Results showed that the phenolic sites appear to have a higher affinity for metal ions than the carboxyl sites. Wu et al. [239] reported that the removal efficiency increased sharply in the $\mathrm{pH}$ ranged from 2 to 4 and then reached reached a quasi-plateau. When the $\mathrm{pH}$ of solution increased to 4 , more than $90 \%$ of $\mathrm{Cr}$ (III) in solution was adsorbed. The adsorption was due to the competition between $\mathrm{Cr}$ (III) and proton for the binding sites on the lignin surface. That's to say, when the $\mathrm{pH}$ of solution is very low, the adsorption will decrease because of the competition of excess proton with $\mathrm{Cr}$ (III). Therefore, less amount of $\mathrm{Cr}$ (III) would be adsorbed. Results also indicated that the mechanism of $\mathrm{Cr}$ (III) ions adsorption is ion-exchange [248, 249]. The removal of $\mathrm{Cr}$ (III) by lignin suggested that organic materials in wastewater may decrease the Cr (III) adsorption owing to the complexification of organic materials by the binding site of lignin surface [239]. Besides, the acidity constant of the functional group sites of the lignin-based biosorbents was also an important factor in metal ions adsorption. The surface acidity constants were also attributed to the carboxylicand phenolic-type surfaces groups [247]. In acidic environment, a low $\mathrm{pH}$ value led to the protonation of the biosorbent, especially the functional groups such as carboxyl and hydroxyl groups on the surface of the lignin-based biosorbents, thus resulting in less negative charges of the lignin surface. Hence, the $\mathrm{Cr}$ and the dye are mainly adsorbed onto the functional groups of lignin. The lower $\mathrm{pH}$ to some extent enhances the metal ions removal efficiency from aqueous phase. For example, da Silva et al. [232] investigated the adsorption of Brilliant Red (BR $)^{-2}$ dye by $\mathrm{Fe}$ (III) ion complexed lignin in the $\mathrm{pH}$ range from 2 to 10. Results showed that the functional groups (hydroxyl and carboxyl) of the lignin were rapidly protonated at low $\mathrm{pH} 2$, and the maximum adsorption capacity of BR-2 dye was $73.6 \mathrm{mg} / \mathrm{g}$. The dye removal was remarkably decreased at $\mathrm{pH}$ 2. At low $\mathrm{pHs}$, the dominant species in solution are $\mathrm{HCrO}^{4-}$ and $\mathrm{Cr}_{2} \mathrm{O}_{7}{ }^{2-}$. As shown in Table 3, the adsorption of $\mathrm{Cr}$ in the low $\mathrm{pH}$ values was mainly owing to the electrostatic attraction which occurred between the protonated functional groups of the lignin-based biosorbents and $\mathrm{Cr}$ containing ions. When the $\mathrm{pH}$ of the solution ranged from 3 to 6, the dominant species of $\mathrm{Cr}(\mathrm{VI})$ is $\mathrm{Cr}_{2} \mathrm{O}_{7}{ }^{2-}$. The adsorption of $\mathrm{Cr}(\mathrm{VI})$ will be decreased owing to the electrostatic attraction between the biosorbents and $\mathrm{Cr}$ (VI) species because the electron donor decreased by raising the $\mathrm{pH}$. Furthermore, Yusof and Malek [250] indicated that the existed $\mathrm{Cr}_{2} \mathrm{O}_{7}{ }^{2-}$ ion needs two adjacent sorption sites on the surface of the biosorbents to bond firmly. Therefore, the adsorption probability of the $\mathrm{Cr}(\mathrm{VI})$ oxoanion decreased. When the $\mathrm{pH}$ value > 6 , much content of the $\mathrm{OH}^{-}$ anion will be present in the aqueous solution and compete with chromate ions for the sorption sites on the surface of the lignin-based biosrobents.

Another removal mechanism of the $\mathrm{Cr}(\mathrm{VI})$ adsorption is the reduction of $\mathrm{Cr}$ (VI) to $\mathrm{Cr}$ (III) by both ligninbased biosorbents and other natural biomaterials. Park et al. [251-253] claimed that the reduction of Cr (VI) include direct and indirect reaction mechanisms. The direct reduction mechanism depends on the electrondonor groups of the biosorbents. However, the indirect reduction mechanism includes three steps: 1) The $\mathrm{Cr}$ (VI) oxoanion was adsorbed on the positively charged groups of the biosorbents. 2) The reduction of $\mathrm{Cr}(\mathrm{VI})$ to $\mathrm{Cr}$ (III) happened by the adjacent electron-donor groups of the biosorbents. 3) The positively charged $\mathrm{Cr}$ (III) was released to the aqueous solution by repulsion reaction with the positively functional groups of biosorbents. Therefore, the reduction mechanism is mainly depends on the adjacent groups of the lignin-based biosorbents which could supply the electrons. The lignin-based biosorbents that contains carboxyl, carbonyl, and methoxyl groups, might be good choice for $\mathrm{Cr}$ (VI) reduction reaction. In addition, the study of the kinetic and thermodynamics in the $\mathrm{Cr}$ (VI) adsorption can also provide important information on the mechanisms of lignin-based biosorbents [254].

\section{Conclusions}

In recent years, the utilization of low-cost lignocellulosic biomass as biosorbents for the removal of heavy metals from wastewater has been widely studied. Lignin, a waste product of the paper industry, is the second most abundant natural polymer, has showed several advantages in wastewater treatments because of the low-cost, high adsorption capacity, easy recovery of biosorbents, and possibility of metal recovery. Lignin has been efficiently extracted from different lignocellulosic biomass using various solvents by a large number of studies. The structural feature and physicochemical properties of the different lignin samples have been thoroughly investigated. In addition, the functional groups such as hydroxyl, carbonyl, and methoxyl of lignin are characterized to indicate the utilization of the material in different research areas.

Lignin is utilized to produce biosorbents in wastewater treatment, such as heavy metal adsorption from dyeing and tannery wastewater. In order to improve the adsorption capacity, chemical modification of lignin is necessary, such as alkylation, sulfonation, amination, carboxylation, acylation, nitration, oxidation, etc. The adsorption capacities of heavy metal ions have been investigated by different factors, such as temperature, adsorbent dose, interaction time, $\mathrm{pH}$, and heavy metal ion concentration. In most cases, it was found that the solution $\mathrm{pH}$ affects the adsorption process. In general, to obtain high heavy metal 
removal efficiency, the most suitable $\mathrm{pH}$ should range from 1.0 to 3.0. The adsorption mechanism has been characterized by the Langmuir and Freundlich model of adsorption between the lignin-based biorsorbents and heavy metal ions. The results showed that lignin-based biosorbents were effective in $\mathrm{Cr}$ (III)/Cr (VI) removal. This will provide an economic and cost-effective approach in the removal of $\mathrm{Cr}$ and dyes from the tannery wastewater.

The widespread use of lignin-based biosorbents in industry was owing to their local availability, economic feasibility, and high efficiency. If the desirable characteristics of the adsorbents from various lignin-based wastes realized, it may be considered as the best alternative in wastewater treatment applications to expensive commercial adsorbents. Although the results obtained from lignin-based biosorbents are promising, there is a little information on the relationship between the lignin molecule, structure, and the metal ions, especially the molecular weight, functional groups, and structural characteristics of the lignin-based biosorbents. Therefore, the fundamental and more detailed systematic studies are still necessary which will determine the adsorption mechanisms and results. In summary, the low-cost lignin-based biosorbents offer a lot of benefits and will provide a possibility of tannery wastewater treatment in a commercial scale in the future.

\section{Acknowledgements}

Not applicable.

\section{Authors' contributions}

Conceived and designed the review, and critical revised the manuscript: RCS; Wrote and revised the manuscript: BW and YCS. All authors read and approved the final manuscript.

\section{Funding}

We are grateful for the financial support by the Central Universities, Beijing Forestry University (2017-17), Chang'an University (300102299203); National Science Foundation of China (41702367); the National Science Foundation of China for a Key Project (31430092); the National Key R\&D Program of China (2017YFB0307903)

\section{Availability of data and materials}

The datasets analyzed during the current review are available in the references, which have been specified in the article.

\section{Competing interests}

The authors declare that they have no competing interests.

\section{Author details}

'Beijing Key Laboratory of Lignocellulosic Chemistry, Beijing Forestry University, Beijing, China. ${ }^{2}$ Key Laboratory of Subsurface Hydrology and Ecological Effects in Arid Region, Ministry of Education, School of Environmental Science and Engineering, Chang'an University, Xi'an, China. ${ }^{3}$ Center for Lignocellulose Science and Engineering, and Liaoning Key Laboratory Pulp and Paper Engineering, Dalian Polytechnic University, Dalian, China.
Received: 24 January 2019 Accepted: 19 June 2019

Published online: 29 July 2019

\section{References}

1. Shanker AK, Cervantes C, Loza-Tavera, H, Avudainayagam S. Chromium toxicity in plants. Environ Int. 2005;31(5):739-53.

2. Sarin V, Sarvinder Singh T, Pant KK. Thermodynamic and breakthrough column studies for the selective sorption of chromium from industrial effluent on activated eucalyptus bark. Bioresour Technol. 2006;97:1986-93.

3. Mohan D, Pittman C. Activated carbons and low cost adsorbents for remediation of tri-and hexavalent chromium from water. J Hazard Mater. 2006;137:762-811

4. Richard F, Bourg A. Aqueous geochemistry of chromium: a review. Water Res. 1991;25:807-16.

5. Owlad M, Aroua MK, Daud WAW, Baroutian S. Removal of hexavalent chromium-contaminated water and wastewater: a review. Water Air Soil Pollut. 2009;200(1-4):59-77.

6. Krejpcio Z. Essentiality of chromium for human nutrition and health. Pol J Environ Stud. 2001;10(6):399-404

7. Carlisle DL, Pritchard DE, Singh J, Owens BM, Blankenship LJ, Orenstein JM, Patierno SR. Apoptosis and P53 induction in human lung fibroblasts exposed to chromium (VI): effect of ascorbate and tocopherol. Toxicol Sci. 2000;55(1):60-8

8. Biswas J, Bose P, Mandal S, Paul AK. Reduction of hexavalent chromium by a moderately halophilic bacterium, Halomonas smyrnensis KS802 under saline environment. Environ Sustainability. 2018:1(4):411-23.

9. Zhu J, Gu H, Guo J, Chen M, Wei H, Luo Z, Haldolaarachchige N. Mesoporous magnetic carbon nanocomposite fabrics for highly efficient $\mathrm{Cr}$ (VI) removal. J Mater Chem A. 2014;2(7):2256-65.

10. Zhu J, Wei S, Gu H, Rapole SB, Wang Q, Luo Z, Guo Z. One-pot synthesis of magnetic graphene nanocomposites decorated with core@ double-shell nanoparticles for fast chromium removal. Environ Sci Technol. 2011;46(2):977-85.

11. Werber JR, Osuji CO, Elimelech M. Materials for next-generation desalination and water purification membranes. Nat Rev Mater. 2016;1(5):16018.

12. Vinodhini V, Das N. Biowaste materials as sorbents to remove chromium (VI) from aqueous environment-a comparative study. J Agric Biol Sci. 2009;4(6): 19-23.

13. Vvu S, Argyropoulos D. An improved method for Isolating lignin in high yield and purity. J Pulp Pap Sci. 2003;29:235-40.

14. Nair V, Panigrahy A, Vinu R. Development of novel chitosan-lignin composites for adsorption of dyes and metal ions from wastewater. Chem Eng J. 2014;254:491-502

15. Song Z, Li W, Liu W, Yang Y, Wang N, Wang H, Gao H. Novel magnetic lignin composite sorbent for chromium (VI) adsorption. RSC Adv. 2015;5(17): 13028-35.

16. Kwak HW, Woo H, Kim EH, Lee KH. Water-resistant lignin/poly (vinyl alcohol) blend fibers for removal of hexavalent chromium. Fibers Polymers. 2018; 19(6):1175-83.

17. Björkman A. Isolation of lignin from finely divided wood with neutral solvents. Nature. 1954:174:1057-8.

18. Wang HM, Wang $B$, Wen JL, Yuan $T Q$, Sun RC. Structural characteristics of lignin macromolecules from different Eucalyptus species. ACS Sustain Chem Eng. 2017;5(12):11618-27.

19. Ikeda T, Holtman K, Kadla JF, Chang HM, Jameel H. Studies on the effect of ball milling on lignin structure using a modified DFRC method. J Agric Food Chem. 2001;50:129-35.

20. Fujimoto A, Matsumoto Y, Chang HM, Meshitsuka G. Quantitative evaluation of milling effects on lignin structure during the isolation process of milled wood lignin. J Wood Sci. 2005:51(1):89-91.

21. Chang HM, Cowling EB, Brown W. Comparative studies on cellulolytic enzyme lignin and milled wood lignin of sweetgum and spruce. Holzforschung. 1975;29(5):153-9.

22. Wang H, Wang B, Sun D, Shi Q, Zheng L, Wang S, Sun R. Unraveling the Fate of Lignin from Eucalyptus and Poplar during Integrated Delignification and Bleaching. ChemSusChem. 2019;12(5):1059-68.

23. Chen TY, Wang B, Shen XJ, Li HY, Wu YY, Wen JL, Sun RC. Assessment of structural characteristics of regenerated cellulolytic enzyme lignin based on a mild DMSO/[Emim] OAc dissolution system from triploid of Populus tomentosa Carr. RSC Adv. 2017;7(6):3376-87.

24. Wu S, Argyropoulos D. An improved method for isolating lignin in high yield and purity. J Pulp Pap Sci. 2003;29:235-40. 
25. Chen TY, Wang B, Wu YY, Wen JL, Liu CF, Yuan TQ, Sun RC. Structural variations of lignin macromolecule from different growth years of triploid of Populus tomentosa Carr. Int J Biol Macromol. 2017;101:747-57.

26. Wang HM, Wang B, Wen JL, Wang SF, Shi Q, Sun RC. Green and efficient conversion strategy of Eucalyptus based on mechanochemical pretreatment. Energy Convers Manag. 2018;175:112-20.

27. Li HY, Wang B, Wen JL, Cao XF, Sun SN, Sun RC. Availability of four energy crops assessing by the enzymatic hydrolysis and structural features of lignin before and after hydrothermal treatment. Energy Convers Manag. 2018;155:58-67.

28. Sixta, H., (Ed.), (2008). Handbook of Pulp, Wiley-VCH Verlag GmbH.

29. Rosli WW, Leh CP, Zainuddin Z, Tanaka R. Optimisation of soda pulping variables for preparation of dissolving pulps from oil palm fibre. Holzforschung. 2003;57(1):106-13

30. Strassberger Z, Tanase S, Rothenberg G. The pros and cons of lignin valorisation in an integrated biorefinery. RSC Adv. 2014;4(48):25310-8.

31. Al Arni S. Extraction and isolation methods for lignin separation from sugarcane bagasse: a review. Ind Crop Prod. 2018;115:330-9.

32. Mousavioun P, Doherty W. Chemical and thermal properties of fractionated bagasse soda lignin. Ind Crops Prod. 2010;1:52-8.

33. Saake B, Lehnen R. Lignin, in Ullmann's encylopedia of industrial chemistry. Weinheim: Wiley-VCH Verlag GmbH \& Co. KGaA; 2012. p. 21-36.

34. Zakzeski J, Bruijnincx $P$, Jongerius $A$, Weckhuysen $B$. The catalytic valoriza- tion of lignin for the production of renewable chemicals. Chem Rev. 2010;110:3552-99.

35. Saake B, Lehnen R. Lignin. Ullmann's Encyclopedia of Industrial Chemistry; 2000

36. Fredheim GE, Braaten SM, Christensen BE. Molecular weight determination of lignosulfonates by size-exclusion chromatography and multi-angle laser light scattering. J Chromatogr A. 2002;942(1-2):191-9.

37. Braaten SM, Christensen BE, Fredheim GE. Comparison of molecular weight and molecular weight distributions of softwood and hardwood lignosulfonates. J Wood Chem Technol. 2003;23(2):197-215.

38. El Hage R, Brosse N, Sannigrahi P, Ragauskas A. Effects of process severity on the chemical structure of Miscanthus ethanol organosolv lignin. Polym Degrad Stab. 2010;95(6):997-1003.

39. Lindner A, Wegener $G$. Characterization of lignins from organosolv pulping according to the organocell process PART 1. Elemental analysis, nonlignin portions and functional groups. J Wood Chem Technol. 1988;8(3):323-40.

40. Sun YC, Wen JL, Xu F, Sun RC. Fractional and structural characterization of organosolv and alkaline lignins from Tamarix austromogoliac. Sci Res Essays. 2010;5(24):3850-64.

41. Wang B, Shen XJ, Wen JL, Sun RC. A mild $\mathrm{AlCl}_{3}$-catalyzed ethanol pretreatment and its effects on the structural changes of Eucalyptus wood lignin and the saccharification efficiency. RSC Adv. 2016;6(63):57986-95.

42. Wang B, Shen XJ, Wen $J$, Xiao L, Sun RC. Evaluation of organosolv pretreatment on the structural characteristics of lignin polymers and followup enzymatic hydrolysis of the substrates from Eucalyptus wood. Int J Biol Macromol. 2017:97:447-59.

43. Brosse N, Sannigrahi $P$, Ragauskas A. Pretreatment of Miscanthus $x$ giganteus using the ethanol organosolv process for ethanol production. Ind Eng Chem Res. 2009;48(18):8328-34

44. Sannigrahi P, Ragauskas AJ, Tuskan GA. Poplar as a feedstock for biofuels: a review of compositional characteristics. Biofuels Bioprod Biorefin. 2010;4(2):209-26.

45. Linh TN, Fuijta H, Sakoda A. Release kinetics of esterified p-coumaric acid and ferulic acid from rice straw in mild alkaline solution. Bioresour Technol. 2017;232:192-203.

46. Ralph J, Lundquist K, Brunow G, Lu F, Kim H, Schatz PF, Boerjan W. Lignins: natural polymers from oxidative coupling of 4-hydroxyphenyl-propanoids. Phytochem Rev. 2004;3(1-2):29-60.

47. Vanholme R, Demedts B, Morreel K, Ralph J, Boerjan W. Lignin biosynthesis and structure. Plant Physiol. 2010;153(3):895-905.

48. Lu F, Ralph J. The DFRC method for lignin analysis. 2. Monomers from isolated lignins. J Agric Food Chem. 1998;46(2):547-52.

49. Hu Z, Foston MB, Ragauskas AJ. Biomass characterization of morphological portions of Alamo switchgrass. J Agric Food Chem. 2011;59(14):7765-72.

50. Faix O. Classification of lignins from different botanical origins by FT-IR spectroscopy. Holzforschung. 1991;45(1):21-8.

51. Marques AV, Pereira $H$, Rodrigues J, Meier D, Faix O. Isolation and comparative characterization of a Björkman lignin from the saponified cork of Douglas-fir bark. J Anal Appl Pyrolysis. 2006;77(2):169-76.

52. Sun SL, Wen JL, Ma MG, Li MF, Sun RC. Revealing the structural inhomogeneity of lignins from sweet sorghum stem by successive alkali extractions. J Agric Food Chem. 2013;61:4226-35.
53. Tao Y, Li S, Li P, Wu Q. Thermogravimetric analyses (TGA) of lignins isolated from the residue of corn Stover bioethanol (CSB) production. Holzforschung. 2016;70(12):1175-82.

54. Yang Q, Wu S. Thermogravimetric characteristics of wheat straw lignin. Cellulose Chem Technol. 2009;43(4):133-9.

55. Kubo S, Kadla JF. Thermal decomposition study of isolated lignin using temperature modulated TGA. J Wood Chem Technol. 2008;28(2):106-21.

56. Lundquist KNUT, Olsson TOMAS. NMR studies of lignins. 1. Signals due to protons in formyl groups. Acta Chem Scand B. 1977;31(9):788-92.

57. Jiang $N, P u$ Y, Ragauskas AJ. Rapid determination of lignin content via direct dissolution and $\mathrm{H}-1$ NMR analysis of plant cell walls. ChemSusChem. 2010;3:1285-9.

58. Argyropoulos DS, Bolker HI, Heitner C, Archipov Y. 31P NMR spectroscopy in wood chemistry. Part IV. Lignin models: spin lattice relaxation times and solvent effects in 31 P NMR. Holzforschung. 1993:47(1):50-6.

59. Sannigrahi $P$, Ragauskas AJ, Miller SJ. Lignin structural modifications resulting from ethanol organosolv treatment of loblolly pine. Energy Fuel. 2009;24(1):683-9.

60. Pu Y, Cao S, Ragauskas AJ. Application of quantitative 31P NMR in biomass lignin and biofuel precursors characterization. Energy Environ Sci. 2011;4(9):3154-66

61. Guerra A, Filpponen I, Lucia LA, Argyropoulos DS. Comparative evaluation of three lignin isolation protocols for various wood species. J Agric Food Chem. 2006;54(26):9696-705.

62. Holtman KM, Chang HM, Kadla JF. Solution-state nuclear magnetic resonance study of the similarities between milled wood lignin and cellulolytic enzyme lignin. J Agric Food Chem. 2004;52(4):720-6.

63. Yuan TQ, Sun SN, Xu F, Sun RC. Structural characterization of lignin from triploid of Populus tomentosa Carr. J Agric Food Chem. 2011;59(12):6605-15.

64. Akim LG, Argyropoulos DS, Jouanin L, Leple JC, Pilate G, Pollet B, Lapierre C. Quantitative 31PNMRspectroscopy of lignins from transgenic poplars. Holzforschung. 2001;2001(55):386-90.

65. Tohmura SI, Argyropoulos DS. Determination of arylglycerol- $\beta$-aryl ethers and other linkages in lignins using DFRC/ ${ }^{31}$ P NMR. J Agric Food Chem. 2001;49(2):536-42

66. Sannigrahi P, Ragauskas AJ, Miller SJ. Effects of two-stage dilute acid pretreatment on the structure and composition of lignin and cellulose in loblolly pine. BioEnergy Res. 2008;1(3-4):205-14.

67. Stücker A, Podschun J, Saake B, Lehnen R. A novel quantitative ${ }^{31}$ P NMR spectroscopic analysis of hydroxyl groups in lignosulfonic acids. Anal Methods. 2018;10(28):3481-8.

68. Capanema EA, Balakshin MY, Kadla JF. A comprehensive approach for quantitative lignin characterization by NMR spectroscopy. J Agric Food Chem. 2004;52(7):1850-60.

69. Capanema EA, Balakshin MY, Kadla JF. Quantitative characterization of a hardwood milled wood lignin by nuclear magnetic resonance spectroscopy. J Agric Food Chem. 2005:53(25):9639-49.

70. Capanema EA, Balakshin MY, Chen CL, Gratzl JS, Gracz H. Structural analysis of residual and technical lignins by $1 \mathrm{H}-13 \mathrm{C}$ correlation 2D NMRspectroscopy. Holzforschung. 2001;55(3):302-8.

71. Shimada M, Fukuzuka T, Higuchi T. Ester linkages of p-coumaric acid in bamboo and grass lignins. Tappi. 1971;54:72-8.

72. Nakamura $Y$, Higuchi T. Ester linkage of p-coumaric acid in bamboo lignin. Holzforschung. 1976;30:187-91.

73. Yue F, Lu F, Ralph S, Ralph J. Identification of 4-O-5-units in softwood lignins via definitive lignin models and NMR. Biomacromolecules. 2016;17(6):1909-20.

74. Martinez AT, Rencoret J, Marques G, Gutiérrez A, Ibarra D, Jiménez-Barbero J, del Río JC. Monolignol acylation and lignin structure in some nonwoody plants: a 2D NMR study. Phytochemistry. 2008;69:2831-43.

75. Wen JL, Sun Z, Sun YC, Sun SN, Xu F, Sun RC. Structural characterization of alkali-extractable lignin fractions from bamboo. J Biobased Mat Bioenergy. 2010;4(4):408-25.

76. Yelle DJ, Wei D, Ralph J, Hammel KE. Multidimensional NMR analysis reveals truncated lignin structures in wood decayed by the brown rot basidiomycete Postia placenta. Environ Microbiol. 2011;13(4):1091-100.

77. Del Rio JC, Rencoret J, Marques G, Li J, Gellerstedt G, Jiménez-Barbero J, Gutiérrez A. Structural characterization of the lignin from jute (Corchorus capsularis) fibers. J Agric Food Chem. 2009;57(21):10271-81.

78. Ragauskas AJ, Beckham GT, Biddy MJ, Chandra R, Chen F, Davis MF, Langan $P$. Lignin valorization: improving lignin processing in the biorefinery. Science. 2014;344(6185):1246843. 
79. Laurichesse S, Avérous L. Chemical modification of lignins: towards biobased polymers. Prog Polym Sci. 2014;39:1266-90.

80. Duval A, Lawoko M. A review on lignin-based polymeric, micro-and nanostructured materials. React Funct Polym. 2014;85:78-96.

81. Yuan $T Q, X u F$, Sun RC. Role of lignin in a biorefinery: separation characterization and valorization. J Chem Technol Biotechnol. 2013;88(3):346-52

82. Azadi P, Inderwildi OR, Farnood R, King DA. Liquid fuels, hydrogen and chemicals from lignin: a critical review. Renew Sust Energ Rev. 2013;21:506-23.

83. Fan L, Zhang $Y$, Liu S, Zhou N, Chen P, Cheng Y, Addy M, Lu Q, Omar MM, Liu Y, Wang Y, Dai L, Anderson E, Peng P, Lei H, Ruan R. Bio-oil from fast pyrolysis of lignin: effects of process and upgrading parameters. Bioresour Technol. 2017;241:1118-26.

84. Ferrini P, Rinaldi R. Catalytic biorefining of plant biomass to non-pyrolytic lignin bio-oil and carbohydrates through hydrogen transfer reactions. Angew Chem Int Ed. 2014;53:8634-9.

85. Wang H, Pu Y, Ragauskas A, Yang B. From lignin to valuable productsstrategies, challenges, and prospects. Bioresour Technol. 2019;271:449-61.

86. Huber GW, Iborra S, Corma A. Synthesis of transportation fuels from biomass: chemistry, catalysts, and engineering. Chem Rev. 2006;106(9):4044-98.

87. Van den Bosch S, Koelewijn SF, Renders T, Van den Bossche G, Vangeel T, Schutyser W, Sels BF. Catalytic strategies towards lignin-derived chemicals. Top Curr Chem. 2018;376(5):36.

88. Thakur VK, Thakur MK, Raghavan P, Kessler MR. Progress in green polymer composites from lignin for multifunctional applications: a review. ACS Sustain Chem Eng. 2014;2(5):1072-92.

89. Ferdosian F, Yuan Z, Anderson M, Xu CC. Thermal performance and thermal decomposition kinetics of lignin-based epoxy resins. J Anal and Appl Pyrolysis. 2016;119:124-32.

90. Wang C, Kelley SS, Venditti RA. Lignin-Based Thermoplastic Materials ChemSusChem. 2016:9(8):770-83.

91. Espinoza-Acosta JL, Torres-Chávez PI, Olmedo-Martínez JL, Vega-Rios A, Flores-Gallardo S, Zaragoza-Contreras EA. Lignin in storage and renewable energy applications: a review. Journal of energy chemistry. J Energy Chem. 2018;27(5):1422-38.

92. Qiao W, Li S, Guo G, Han S, Ren S, Ma Y. Synthesis and characterization of phenol-formaldehyde resin using enzymatic hydrolysis lignin. J Ind Eng Chem. 2015;21:1417-22.

93. Yang S, Zhang Y, Yue W, Wang W, Wang YY, Yuan TQ, Sun RC. Valorization of lignin and cellulose in acid-steam-exploded corn stove by a moderate alkaline ethanol post-treatment based on an integrated biorefinery concept. Biotechnology for Biofuels. 2016;9(1):238.

94. Yang S, Wen JL, Yuan TQ, Sun RC. Characterization and phenolation of biorefinery technical lignins for lignin-phenol-formaldehyde resin adhesive synthesis. RSC Adv. 2014;4(101):57996-8004.

95. Yang S, Zhang Y, Yuan TQ, Sun RC. Lignin-phenol-formaldehyde resin adhesives prepared with biorefinery technical lignins. J Appl Polym Sci. 2015;132(36):42493.

96. Yang S, Wu JQ, Zhang Y, Yuan TQ, Sun RC. Preparation of lignin-phenolformaldehyde resin adhesive based on active sites of technical lignin. J Biobased Mat Bioenergy. 2015;9(2):266-72.

97. Wang B, Sun D, Wang HM, Yuan TQ, Sun RC. Green and facile preparation of regular lignin nanoparticles with high yield and their natural broadspectrum sunscreens. ACS Sustain Chem Eng. 2019;7(2):2658-66.

98. Ago M, Tardy BL, Wang L, Guo J. Supramolecular assemblies of lignin into nano-and microparticles. MRS Bull. 2017:42(5):371-8.

99. Ago M, Huan S, Borghei M, Raula J, Kauppinen El, Rojas OJ. Highthroughput synthesis of lignin particles $(\sim 30 \mathrm{~nm}$ to $\sim 2 \mu \mathrm{m})$ via aerosol flow reactor: size fractionation and utilization in Pickering emulsions. ACS Appl Mater Interfaces. 2016;8(35):23302-10.

100. Tardy B, Richardson JJ, Guo J, Lehtonen J, Ago M, Rojas O. Lignin nano- and microparticles as template for nanostructured materials: formation of hollow metal-phenolic capsules. Green Chem. 2018;20(6):1335-44.

101. Kai D, Tan MJ, Chee PL, Chua YK, Yap YL, Loh XJ. Towards lignin-based functional materials in a sustainable world. Green Chem. 2016;18(5):1175-200.

102. Chatterjee S, Saito T. Lignin-derived advanced carbon materials. ChemSusChem. 2015;8(23):3941-58

103. Puziy AM, Poddubnaya Ol, Sevastyanova O. Carbon materials from technical Lignins: recent advances. Top Curr Chem. 2018;376(4):33.

104. Jeon JW, Zhang L, Lutkenhaus JL, Laskar DD, Lemmon JP, Choi D, Fernandez CA. Controlling porosity in lignin-derived nanoporous carbon for supercapacitor applications. ChemSusChem. 2015;8(3):428-32.
105. Farag S, Chaouki J. Economics evaluation for on-site pyrolysis of Kraft lignin to value-added chemicals. Bioresour Technol. 2015;175:254-61.

106. Li C, Zhao X, Wang A, Huber GW, Zhang T. Catalytic transformation of lignin for the production of chemicals and fuels. Chem Rev. 2015;115:11559-624.

107. Ma R, Xu Y, Zhang X. Catalytic oxidation of biorefinery lignin to valueadded chemicals to support sustainable biofuel production. ChemSusChem. 2015:8:24-51.

108. Bailey SE, Olin TJ, Bricka RM, Adrian DD. A review of potentially low-cost sorbents for heavy metals. Water Res. 1999;33:2469-79.

109. Li Z, Zhang J, Qin L, Ge Y. Enhancing antioxidant performance of lignin by enzymatic treatment with laccase. ACS Sustain Chem Eng. 2018;6:2591-5.

110. Wang B, Wen JL, Sun SL, Wang HM, Wang SF, Liu QY, Sun RC. Chemosynthesis and structural characterization of a novel lignin-based biosorbent and its strong adsorption for Pb (II). Ind Crop Prod. 2017;108:72-80.

111. Li Z, Ge Y, Wan L. Fabrication of a green porous lignin-based sphere for the removal of lead ions from aqueous media. J Hazard Mater. 2015;285:77-83.

112. Lian E, Shi R, Deng Y, Zhu H, Ma Y. Adsorption of low cross-linking density hydrogel OMMT/acid hydrolysis lignin grafted polyacrylic acid for cd (II). AIP Conf Proc. 2017;1820:020001.

113. Demirbas A. Adsorption of co (II) and hg (II) from water and wastewater onto modified lignin. Energy Sources Part A. 2007;29:117-23.

114. Li Y, Sarkanen S. Alkylated Kraft lignin-based thermoplastic blends with aliphatic polyesters. Macromolecules. 2002;35(26):9707-15.

115. Li Y, Sarkanen S. Miscible blends of Kraft lignin derivatives with low-Tg polymers. Macromolecules. 2005;38(6):2296-306.

116. Cunxiu G, Donghua C, Wanjun T, Changhua L. Properties and thermal degradation study of blend films with poly (4-vinylpyridine) and lignin. J Appl Polym Sci. 2005;97(5):1875-9.

117. Kubo S, Kadla JF. Poly (ethylene oxide)/Organosolv lignin blends: relationship between thermal properties, chemical structure, and blend behavior. Macromolecules. 2004;37(18):6904-11.

118. Kubo S, Kadla JF. Kraft lignin/poly (ethylene oxide) blends: effect of lignin structure on miscibility and hydrogen bonding. J Appl Polym Sci. 2005:98(3):1437-44.

119. Thielemans W, Wool RP. Lignin esters for use in unsaturated thermosets: lignin modification and solubility modeling. Biomacromolecules. 2005;6(4): 1895-905.

120. Adcock T, Shah V, Chen MJ, Mqqeister JJJ. Graft copolymers of lignin as hydrophobic agents for plastic (wood-filled) composites. J Appl Polym Sci. 2003:89(5):1266-76.

121. Meister JJ. Polymer modification: principles, techniques, and applications. New York: Marcel Dekker; 2000.

122. Jasiukaitytè-Grojzdek E, Kunaver M, Crestini C. Lignin structural changes during liquefaction in acidified ethylene glycol. J Wood Chem Technol. 2012;32(4):342-60.

123. Korich AL, Clarke KM, Wallace D, lovine PM. Chemical modification of a lignin model polymer via Arylboronate Ester formation under mild reaction conditions. Macromolecules. 2009;42:5906-8.

124. Lai C, Tu C, Xia C, Shi Z, Sun S, Yong Q, Yu S. Lignin alkylation enhances enzymatic hydrolysis of lignocellulosic biomass. Energy Fuels. 2017;31(11):12317-26.

125. Couto SR, Herrera JLT. Industrial and biotechnological applications of laccases: a review. Biotechnol Adv. 2006;24:500-13.

126. Ishihara T, Miyazaki M. Oxidation of milled wood lignin by fungal laccase. Mokuzai Gakkaishi. 1972;18:415-9.

127. Leonowicz A, Szklarz G, Wojtas-Wasilewska M. The effect of fungal laccase on fractionated lignosulphonates (Peritan Na). Phytochemistry. 1985;24:393-6.

128. Xu QH, Qin MH, Shi SL, Jin LQ, Fu YJ. Structural changes in lignin during the deinking of old newsprint with laccasevioluric acid system. Enzym Microb Technol. 2006:39:969-75.

129. Jamiu ZA, Saleh TA, Ali SA. Biogenic glutamic acid-based resin: its synthesis and application in the removal of cobalt (II). J Hazard Mater. 2017:327:44-54.

130. Zhao X, Zhang G, Jia Q, Zhao C, Zhou W, Li W. Adsorption of cu (II), Pb (II), $\mathrm{co}(\mathrm{II}), \mathrm{Ni}(\mathrm{II})$, and cd (II) from aqueous solution by poly (aryl ether ketone) containing pendant carboxyl groups (PEK-L): equilibrium, kinetics, and thermodynamics. Chem Eng J. 2011;171:152-8.

131. Li Y, Zhao R, Pang Y, Qiu X, Yang D. Microwave-assisted synthesis of high carboxyl content of lignin for enhancing adsorption of lead. Colloids Surf A. 2018;553:187-94.

132. Adebayo MA, Prola LDT, Lima EC, Puchana-Rosero MJ, Cataluna R, Saucier C, Umpierres CS, Vaghetti JCP, da Silva LG, Ruggiero R. Adsorption of procion 
blue MX-R dye from aqueous solutions by lignin chemically modified with aluminium and manganese. J Hazard Mater. 2014;268:43-50.

133. Shewta K, Jha H. Synthesis and characterization of crystalline carboxymethylated lignin-TEOS nanocomposites for metal adsorption and antibacterial activity. Bioresour Bioprocess. 2016;3(31):1-16.

134. Dizhbite T, Zakis G, Kizima G, Kizima A, Lazareva E, Rossinskaya G, Jurkjane V, Telysheva G, Viesturs U. Lignin-a useful bioresource for the production of sorption-active materials. Bioresour Technol. 1999;67:221-8.

135. Li S, Li J, Yi J, Shan Z. Cleaner beam house processes trial on cattle sofa leather. J Clean Prod. 2010;18:471-7.

136. Teng H, Li M. Study on the cloud point of aqueous mixtures of cationic and anionic surfactants. Chem Res Appl. 2004;16(2):239-41.

137. Sundar VJ, Vedaraman N, Balakrishanan P. Chamois leathers: an approach for accelerated oxidation. J Soc Leather Tech Chem. 2004;88(6):256-9.

138. Krishnamoorthy G, Sadulla S, Sehgal PK, Mandal AB. Green chemistry approaches to leather tanning process for making chrome-free leather by unnatural amino acids. J Hazard Mater. 2012;190(215-216):173-82.

139. Li K, Chen H, Wang Y, Shan Z, Yang J, Brutto P. A salt-free pickling regime for hides and skins using oxazolidine. J Clean Prod. 2009;17(17):1603-6.

140. Saadia RT, Munir HS, Nazia S. Comparative statistical analysis of chrome and vegetable tanning effluents and their effects on related soil. J Hazard Mater. 2009;169:285-90.

141. Ganesan K, Sayeed S, Praveen KS. Greener approach to leather tanning process: D-lysine aldehyde as novel tanning agent for chrome-free tanning. J Clean Prod. 2013:42:277-86.

142. Sundarapandiyan S, Brutto PE, Siddhartha G. Enhancement of chromium uptake in tanning using oxazolidine. J Hazard Mater. 2011;190(1-3):802-9.

143. Brown EM, Taylor MM. Essential chromium? J Am Leather Chem Assoc. 2003:98:408-12.

144. Heidemann E. Fundamentals of leather manufacture. Darmstadt: Eduard Roether KG; 1993.

145. Oliveira LCA, Coura CVZ, Guimaraes IR, Goncalves M. Removal of organic dyes using $\mathrm{Cr}$-containing activated carbon prepared from leather waste. J Hazard Mater. 2011;192:1094-9.

146. Ganesh R, Ramanujam RA. Biological waste management of leather tannery effluents in India: current options and future research needs. Intentional J Environ Eng. 2009:1(2):165-86.

147. Arun Kumar LJP, Viraraghavan T, Ramanujam RA. Evaluation of biodegradability of selected post-tanning chemicals. Fresenius Environ Bull. 2004;13(6):568-73.

148. Danhong S, Qiang H, Wenjun Z, Yulu W, Bi S. Evaluation of environmental impact of typical leather chemicals. Part II. Biodegradability of organic tanning agents by activated sludge. J Soc Leather Technol Chem. 2008;92:59-64.

149. Kaul SN, Nandy T, Vyas RD, Szpyrkowicz L. Waste management in tanneries: experience \& outlook. J Indian Assoc Environ Manag. 2001;28:56-76.

150. Schilling K, Ulrike B, Helmut K, Zessner M. Adapting the Austrian edict on wastewater emissions for tanneries as consequence of foam formation on surface waters. Environ Sci Pol. 2012:23:68-73.

151. Zongo I, Leclerc JP, Maïga HA, Wéthé J, Lapicque F. Removal of hexavalent chromium from industrial wastewater by electrocoagulation: A comprehensive comparison of aluminium and iron electrodes. Sep and Purif Technol. 2009;66(1):159-66.

152. Sahasranaman A, Jackson M. Salinity reduction in tannery effluents in India \& Australia: project review. Canberra: ACIAR; 2005.

153. Galatik A, Duda J, Minarik L. Pressure hydrolysis of leather waste with sodium hydroxide, Czech. Patent, CS, vol. 252; 1988. p. 382.

154. Saranraj P, Sujitha D. Microbial bioremediation of chromium in tannery effluent: a review. Int J Microbiol Res. 2013;4:305-20.

155. Zhang C, Xia F, Long J, Peng B. An integrated technology to minimize the pollution of chromium in wet-end process of leather manufacture. J Clean Prod. 2017;154:276-83.

156. Kimbrough DE, Cohen $Y$, Winer AM. A critical assessment of chromium in the environment. CRC Crit Rev Environ Control. 1999;29(1):1-46.

157. Nataraj SK, Hosamani KM, Aminabhavi TM. Potential application of an electrodialysis pilot plant containing ion-exchange membranes in chromium removal. Desalination. 2007;217:181-90.

158. Sharma AK, Devan RS, Arora M, Kumar R, Ma YR, Babu JN. Reductiveco-precipitated cellulose immobilized zerovalent iron nanoparticles in ionic liquid/water for $\mathrm{Cr}$ (VI) adsorption. Cellulose. 2018;25(9):5259-75.

159. Miretzky P, Fernandez Cirelli A. Cr (VI) and Cr (III) removal from aqueous solution by raw and modified lignocellulosic materials: a review. J Hazard Mater. 2010;180:1-19.
160. Brdar M, Šćiban M, Takači A, Došenović T. Comparison of two and three parameters adsorption isotherm for $\mathrm{Cr}(\mathrm{VI})$ onto Kraft lignin. Chem Eng J. 2012;183:108-11.

161. Albadarin AB, Mangwandi C, Al-Muhtaseb AH, Walker GM, Allen SJ, Ahmad MNM. Modelling and fixed bed column adsorption of $\mathrm{Cr}(\mathrm{VI})$ onto Orthophosphoric acid-activated lignin. Chin J Chem Eng. 2012;20(3):469-77.

162. Kotas J, Stasicka Z. Chromium occurrence in the environment and methods of its speciation. Environ Pollut. 2000;107(3):263-83.

163. Krishnani KK, Ayyappan S. Heavy metals remediation of water using plants and lignocellulosic agrowastes. Rev Environ Contam Toxicol. 2006;188:59-84.

164. IARC (International Agency for Research on Cancer), IARC monographs on the evaluation of carcinogenic risks to humans: overall evaluation of carcinogenicity. An updating of IARC Monographs. (1987). vols. 1-42, Supplement 7, WHO, Lyon, France.

165. Aksu Z. Application of biosorption for the removal of organic pollutants: a review. Process Biochem. 2005;40(3-4):997-1026.

166. Dai L, Zhu W, He L, Tan F, Zhu N, Zhou Q, He M, Hu G. Calcium-rich biochar from crab shell: an unexpected super adsorbent for dye removal. Bioresour Technol. 2018:267:510-6.

167. Shalla A, Bhat MA, Yaseen Z. Hydrogels for removal of recalcitrant organic dyes: a conceptural overview. J Environ Chem Eng. 2018;6:5938-49.

168. Ramakrishnaiah $\mathrm{CR}$, Prathima B. Hexavalent chromium removal from industrial wastewater by chemical precipitation method. Int J Eng Res Appl. 2012;2:599-603.

169. Rengaraj S, Yeon KH, Moon SH. Removal of chromium from water and wastewater by ion exchange resins. J Hazard Mater. 2001;87:273-2787.

170. Patterson RR, Fendorf S. Reduction of hexavalent chromium by amorphous iron sulfide. Environ Sci Technol. 1997:31(7):2039-44.

171. Kingsricharoem N, Polprasert C. Electrochemical precipitation of chromium $\left(\mathrm{Cr}^{6+}\right)$ from an electroplating wastewater. Water Sci Technol. 1995;31(9):109-17.

172. Schoeman JJ, Steyn A, Scurr PJ. Treatment using reverse osmosis of an effluent from stainless steel manufacture. Water Res. 1996;30(9):1979-84.

173. Dakiky M, Khamis M, Manassra A, Mer'eb M. Selective adsorption of chromium (VI) in industrial wastewater using low-cost abundantly available adsorbents. Adv Environ Res. 2002:6(4):533-40.

174. Bishnoi NR, Bajaj M, Sharma N, Gupta A. Adsorption of $\mathrm{Cr}(\mathrm{VI})$ on activated rice husk carbon and activated alumina. Bioresour Technol. 2004;91(3):305-7.

175. Kurniawan TA, Chan GYS, Lo WH, Babel S. Physico-chemical treatment techniques for wastewater laden with heavy metals. Chem Eng J. 2006; 118(1-2):83-98

176. Gheju M, Balcu I. Removal of chromium from $\mathrm{Cr}(\mathrm{VI})$ polluted wastewaters by reduction with scrap iron and subsequent precipitation of resulted cations. J Hazard Mater. 2011:196:131-8.

177. Hawley EL, Deeb RA, Kavanaugh MC, James Jacobs RG. Treatment Technologies for Chromium (VI). In: Guertin J, Jacobs JA, Avakian CP, editors. Chromium (VI) Handbook: CRC Press; 2004. p. 273-308

178. Fathima NN, Rao JR, Nair BU. Chapter 23-effective utilization of solid waste from leather industry. In: The Role of Colloidal Systems in Environmental Protection; 2014. p. 593-609.

179. Edebali S, Pehlivan E. Evaluation of Amberlite IRA96 and Dowex 18 ionexchange resins for the removal of $\mathrm{Cr}(\mathrm{VI})$ from aqueous solution. Chem Eng J. 2010;161(1-2):161-6.

180. Deng Y, Long T, Zhao H, Zhu L, Chen J. Application of porous Nmethylimidazolium strongly basic anion exchange resins on $\mathrm{Cr}(\mathrm{VI})$ adsorption from electroplating wastewater. Sep Sci Technol. 2012; 47(2):256-63.

181. Rengaraj S, Yeon KH, Moon SH. Removal of chromium from water and wastewater by ion exchange resins. J Hazard Mater. 2015;87:273-87.

182. Boopathy R, Sekaran G. Electrochemical treatment of evaporated residue of soak liquor generated from leather industry. J Hazard Mater. 2013;260:286-95.

183. Golder AK, Ray SS. Removal of trivalent chromium by electrocoagulation. Sep Purif Technol. 2007:53(1):33-41.

184. Szpyrkowicz L, Kaul SN, Neti RN, Faveri MD. Influence of anode material on electrochemical oxidation for the treatment of tannery wastewater. Water Res. 2005;39(8):1601-13.

185. Feng JW, Sun YB, Zheng Z, Zhang JB, Li S, Tian YC. Treatment of tannery wastewater by electrocoagulation. J Environ Sci. 2007;19:1409-15.

186. Mella B, Glanert AC, Gutterres M. Removal of chromium from tanning wastewater and its reuse. Process Saf Environ Prot. 2015;95:195-201. 
187. Cassano A, Della Pietra L, Drioli E. Integrated membrane process for the recovery of chromium salts from tannery effluents. Ind Eng Chem Res. 2007; 46(21):6825-30.

188. George J, Ramos A, Shipley HJ. Tanning facility wastewater treatment: analysis of physical-chemical and reverse osmosis methods. J Environ Chem Eng. 2015;3:969-76.

189. Ameri A, Gholami M, Rahimi M, Manmodi M, Moosavi B. Application and optimization in chromium-contaminated wastewater treatment of the reverse osmosis technology. Iran J Public Health. 2008;37(3):77-84.

190. Romero-Dondiz EM, Almilio JE, Rajal VB. Comparison of the performance of ultrafiltration and nanofiltration membranes for the recovery and recycle of tannins in the leather industry. J Cleaner Prod. 2016;135:71-9.

191. Ortiz-Monsalve S, Valente P, Poll E, Jaramillo-Garcia V, Henriques J, Gutterres M. Biodecolourization and biodetoxification of dye-containing wastewaters from leather dyeing by the native fungal strain Trametes villosa SCS-10. Biochem Eng J. 2019;141:19-28.

192. Sivagami K, Sakthivel KP, Nambi IM. Advanced oxidation processes for the treatment of tannery wastewater. J Environ Chem Eng. 2018;6:3656-63.

193. Schrank SG, José HJ, Moreira RFP, Fr MH. Schroder, Elucidation of the behavior of tannery wastewater under advanced oxidation conditions. Chemosphere. 2004:56:411-23.

194. Paschoal FMM, Anderson MA, Zanono MVB. Simultaneous removal of chromium and leather dye from simulated tannery effluent by photoelectrochemistry. J Hazard Mater. 2009;166:531-7.

195. Daneshvar N, Salari D, Aber S. Chromium adsorption and $\mathrm{Cr}(\mathrm{VI})$ reduction to trivalent chromium in aqueous solutions by soya cake. J Hazard Mater. 2002;94(1):49-61.

196. Mohan D, Singh KP, Singh VK. Trivalent chromium removal from wastewater using low cost activated carbon derived from agricultural waste material and activated carbon fabric cloth. J Hazard Mater. 2006:135(1-3):280-95.

197. Udaybhaskar P, Lyengar L, Prabhakara Rao AVS. Hexavalent chromium interaction with chitosan. Appl Polym Sci. 1990;39(3):739-47.

198. Schmuhl R, Krige HM, Keizer K. Adsorption of cu (II) and $\mathrm{Cr}(\mathrm{VI})$ ions by chitosan: kinetics and equilibrium studies. Water SA. 2001;27(1):1-8.

199. Krishnani KK, Meng X, Dupont L. Metal ions binding onto lignocellulosic biosorbent. J Environ Sci Health A. 2009;44(7):688-99.

200. Singh KK, Rastogi R, Hasan SH. Removal of $\mathrm{Cr}(\mathrm{VI})$ from wastewater using rice bran. J Colloid Interface Sci. 2005;290(1):61-8.

201. Krishnani KK, Meng X, Christodoulatos C, Boddu VM. Biosorption mechanism of nine different heavy metals onto biomatrix from rice husk. J Hazard Mater. 2008;153(3):1222-34

202. Wu Y, Cha L, Fan Y, Fang P, Ming Z, Sha H. Activated biochar prepared by pomelo peel using $\mathrm{H}_{3} \mathrm{PO}_{4}$ for the adsorption of hexavalent chromium: performance and mechanism. Water Air Soil Pollut. 2017;228(10):405-18.

203. Dong Z, Zhao J, Du J, Li C, Zhao L. Radiation synthesis of spherical cellulose-based adsorbent for efficient adsorption and detoxification of $\mathrm{Cr}$ (VI). Radiat Phys Chem. 2016;126:68-74.

204. Dong Z, Zhao L. Covalently bonded ionic liquid onto cellulose for fast adsorption and efficient separation of $\mathrm{Cr}(\mathrm{VI})$ : batch, column and mechanism investigation. Carbohydr Polym. 2018;189:190-7.

205. Xu X, Zhang H, Ma C, Gu H, Lou H, Lyu S, Liang C, Kong J, Gu J. A superfast hexavalent chromium scavenger: magnetic nanocarbon bridged nanomagnetite network with excellent recyclability. J Hazard Mater. 2018; 353:166-72.

206. Liu YJ, Liu SL, Li ZW, Ma MG, Wang B. A microwave synthesized mesoporous carbon sponge as an efficient adsorbent for $\mathrm{Cr}(\mathrm{VI})$ removal. RSC Adv. 2018;8:7892-8.

207. Gode F, Pehlivan E. Chromium (VI) adsorption by Brown coals. Energy Sources. 2006;28:447-57

208. Arslan G, Edebali S, Pehlivan E. Physical and chemical factors affecting the adsorption of $\mathrm{Cr}(\mathrm{VI})$ via humic acids extracted from brown coals. Desalination. 2010;255:117-23.

209. Gonzalez MH, Araujo GCL, Pelizaro CB, Menezes EA, Lemos SG, de Sousa GB, Nogueira ARA. Coconut coir as biosorbent for $\mathrm{Cr}(\mathrm{VI})$ removal from laboratory wastewater. J Hazard Mater. 2008;159:252-6.

210. Shen YS, Wang SL, Huang ST, Tzou YM, Huang JH. Biosorption of $\mathrm{Cr}(\mathrm{VI})$ by coconut coir: spectroscopic investigation on the reaction mechanism of $\mathrm{Cr}$ (VI) with lignocellulosic material. J Hazard Mater. 2010;179:160-5.

211. Suksabye $\mathrm{P}$, Thiravetyan P. Cr (VI) adsorption from electroplating plating wastewater by chemically modified coir pith. J Environ Manag. 2012 102:1-8.
212. Ramteke LP, Gogate PR. Removal of copper and hexavalent chromium using immobilized modified sludge biomass based adsorbent. Clean Soil Air Water. 2016:44:1-15.

213. Lyu H, Tang J, Huang Y, Gai L, Zeng EY, Liber K, Gong Y. Removal of hexavalent chromium from aqueous solutions by a novel biochar supported nanoscale iron sulfide composite. Chem Eng J. 2017;322:516-24.

214. Xu Q, Wang Y, Jin L, Wang Y, Qin M. Adsorption of cu (II), Pb (II) and $\mathrm{Cr}(\mathrm{VI})$ from aqueous solutions using black wattle tannin-immobilized nanocellulose. J Hazard Mater. 2017:339:91-9.

215. Nakajima A, Baba Y. Mechanism of hexavalent chromium adsorption by persimmon tannin gel. Water Res. 2004;38:2859-64.

216. Wang J, Ji B, Shu Y, Chen W, Zhu L, Chen F. Cr (VI) removal from aqueous solution using starch and sodium Carboxymethyl cellulose-coated Fe and Fe /Ni nanoparticles. Pol J Environ Stud. 2018;6:2785-92.

217. Dax D, Chávez MS, Xu C, Willför S, Mendonça RT, Sánchez J. Cationic hemicellulose-based hydrogels for arsenic and chromium removal from aqueous solutions. Carbohydr Polym. 2014;111:797-805.

218. Meena AK, Kadirvelu K, Mishra GK, Rajagopal C, Nagar PN. Adsorptive removal of heavy metals from aqueous solution by treated sawdust (Acacia arabica). J Hazard Mater. 2008;150(3):604-11.

219. Uysal M, Ar I. Removal of $\mathrm{Cr}(\mathrm{VI})$ from industrial wastewaters by adsorption part I: determination of optimum conditions. J Hazard Mater. 2007;149(2):482-91.

220. Argun ME, Dursun S, Ozdemir C, Karatas M. Heavy metal adsorption by modified oak sawdust: thermodynamics and kinetics. J Hazard Mater. 2007;141(1):77-85.

221. Gao H, Liu Y, Zeng G, Xu W, Li T, Xia W. Characterization of Cr (VI) removal from aqueous solutions by a surplus agricultural waste-rice straw. J Hazard Mater. 2008;150(2):446-52.

222. Khambhaty $Y$, Mody K, Basha S, Jha B. Kinetics, equilibrium and thermodynamic studies on biosorption of hexavalent chromium by dead fungal biomass of marine Aspergillus Niger. Chem Eng J. 2009;145:489-95.

223. Srinath T, Verma T, Ramteke PW, Garg SK. Chromium (VI) biosorption and bioaccumulation by chromate resistant bacteria. Chemosphere. 2002:48:427-35.

224. Agathian K, Kannammal L, Meenarathi B, Kailash S, Anbarasan R. Synthesis, characterization and adsorption behavior of cotton fiber based Schiff base. Int J Biol Macromolecules. 2018;107(Part A):1102-12.

225. Liu L, Lioa Q, Xie J, Qian Z, Zhu W, Chen X, Su X, Meng R, Yao J. Synthetic control of three-dimensional porous cellulosebased bioadsorbents: correlation between structural feature and metal ion removal capability. Cellulose. 2016;23(6):3819-35

226. Abbas A, Hussain MA, Sher M, Irfan MI, Tahir MN, Tremel W, Hussain SZ, Hussain I. Design, characterization and evaluation of hydroxyethylcellulose based novel regenerable supersorbent for heavy metal ions uptake and competitive adsorption. Int J Biol Macromol. 2017;102:170-80.

227. Velempini T, Pillay K, Mbianda XY, Arotiba OA. Epichlorohydrin crosslinked carboxymethyl cellulose-ethylenediamine imprinted polymer for the selective uptake of $\mathrm{Cr}$ (VI). Int J Biol Macromol. 2017;101:837-44.

228. Luo $X$, Zhang L. High effective adsorption of organic dyes on magnetic cellulose beads entrapping activated carbon. J Hazard Mater. 2009;171(1-3):340-7.

229. Zhu HY, Fu YQ, Jiang JH, Xiao L, Zeng GM, Zhao SL, Wang Y. Adsorption removal of Congo red onto magnetic cellulose/ $\mathrm{Fe}_{3} \mathrm{O}_{4} /$ activated carbon composite: equilibrium, kinetic and thermodynamic studies. Chem Eng J. 2011;173(2):494-502

230. Won SW, Kotte P, Wei W, Lim A, Yun Y-S. Biosorbents for recovery of precious metals. Bioresour Technol. 2014;160:203-12.

231. Wang J, Chen C. Biosorbents for heavy metals removal and their future. Biotechnol Adv. 2009;27(2):195-226.

232. da Silva LG, Ruggiero R, Gontijo Pd M, Pinto RB, Royer B, Lima EC, Fernandes THM, Calvete T. Adsorption of brilliant red 2BE dye from water solutions by a chemically modified sugarcane bagasse lignin. Chem Eng J. 2011:168:620-8

233. Carrott PJM, Carrott MMLR. Lignin—from natural adsorbent to activated carbon: a review. Bioresour Technol. 2007:98:2301-12.

234. Lalvani SB, Hubner A, Wiltowski TS. Chromium adsorption by lignin. Energy Sources. 2000;22:45-56.

235. Yao Q, Xie J, Liu J, Kang H. Adsorption of lead ions using a modified lignin hydrogel. J Polym Res. 2014;21:456-80.

236. Hu LQ, Dai L, Liu R, Si CL. Lignin-graft-poly (acrylic acid) for enhancement of heavy metal ion biosorption. J Mater Sci. 2017:52:13689-99.

237. He ZW, He LH, Yang J, Lv QF. Removal and recovery of au (III) from aqueous solution using a low-cost lignin-based biosorbent. Ind Eng Chem Res. 2013;52:4103-8. 
238. Ge Y, Qin L, Li Z. Lignin microspheres: an effective and recyclable natural polymer-based adsorbent for lead ion removal. Mater Des. 2016;95:141-7.

239. Wu Y, Zhang S, Guo X, Huang H. Adsorption of chromium on lignin. Bioresour Technol. 2008;99:7709-15.

240. Liang FB, Song YL, Huang CP, Zhang J, Chen BH. Adsorption of hexavalent chromium on a lignin-based resin: equilibrium, thermodynamics, and kinetics. J Environ Chem Eng. 2013;1:1301-8.

241. Li FF, Wang XL, Yuan TQ, Sun R. A lignosulfonate-modified graphene hydrogel with ultrahigh adsorption capacity for $\mathrm{Pb}$ (II) removal. J Mater Chem A. 2016:4:11888-96.

242. Chauke VP, Maity A, Chetty A. High-performance towards removal of toxic hexavalent chromium from aqueous solution using graphene oxide-alpha cyclodextrin-polypyrrole nanocomposites. J Mol Liquids. 2015;211:71-7.

243. Gao Y, Yue Q, Gao B, Sun Y, Wang W, Li Q, Wang Y. Preparation of high surface area-activated carbon from lignin of papermaking black liquor by KOH activation for Ni (II) adsorption. Chem Eng J. 2013;217:345-53.

244. Fierro V, Torné-Fernández V, Celzard A. Methodical study of the chemical activation of Kraft lignin with $\mathrm{KOH}$ and $\mathrm{NaOH}$. Microporous Mesoporous Mater. 2007:101:419-31.

245. Albadarin AB, Al-Muhtaseb AH, Walker GM, Allen SJ, Ahmad MNM Retention of toxic chromium from aqueous phase by $\mathrm{H}_{3} \mathrm{PO}_{4}$-activated lignin: effect of salts and desorption studies. Desalination. 2011;274:64-73.

246. Li J, Lin Q, Zhang X, Yan Y. Kinetic parameters and mechanisms of the batch biosorption of $\mathrm{Cr}(\mathrm{VI})$ and $\mathrm{Cr}$ (III) onto Leersia hexandra Swartz biomass. J Colloid Interface Sci. 2009;333:71-7.

247. Guo X, Zhang S, Shan X. Adsorption of metal ions on lignin. J Hazard Mater. 2008;151:134-42

248. Yu LJ, Shukla SS, Dorris KL, Shukla A, Margrave JL. Adsorption of chromium from aqueous solutions by maple sawdust. J Hazard Mater. 2003;100:53-63.

249. Rengaraj S, Joo CK, Kim Y, Yi J. Kinetics of removal of chromium from water and electronic process wastewater by ion exchange resins $1200 \mathrm{H}, 1500 \mathrm{H}$ and IRN97H. J Hazard Mater. 2003;102:257-75.

250. Yusof AM, Malek NANN. Removal of $\mathrm{Cr}(\mathrm{VI})$ and as ( $\mathrm{V}$ ) from aqueous solutions by HDTMA-modified zeolite Y. J Hazard Mater. 2009;162:1019-24.

251. Park D, Yun YS, Park JM. XAS and XPS studies on chromium-binding groups of biomaterial during $\mathrm{Cr}$ (VI) biosorption. J Colloid Interface Sci. 2008;317(1):54-61.

252. Park D, Yun YS, Lee HW, Park JM. Advanced kinetic model of the Cr (VI) removal by biomaterials at various $\mathrm{pHs}$ and temperatures. Bioresour Technol. 2008;99:11141-7.

253. Park D, Ahn CK, Kim YM, Yun YS, Park JM. Enhanced abiotic reduction of $\mathrm{Cr}$ (VI) in a soil slurry system natural biomaterial addition. J Hazard Mater. 2008; 160:422-7.

254. Zhang X, Fu W, Yin Y, Chen Z, Qiu R, Simonnot MO, Wang X. Adsorptionreduction removal of $\mathrm{Cr}(\mathrm{VI})$ by tobacco petiole pyrolytic biochar: batch experiment, kinetic and mechanism studies. Bioresour Technol. 2018;268:149-57.

\section{Publisher's Note}

Springer Nature remains neutral with regard to jurisdictional claims in published maps and institutional affiliations.

\section{Submit your manuscript to a SpringerOpen ${ }^{\circ}$ journal and benefit from:}

- Convenient online submission

- Rigorous peer review

- Open access: articles freely available online

- High visibility within the field

- Retaining the copyright to your article

Submit your next manuscript at $\boldsymbol{\nabla}$ springeropen.com 